\title{
Vancomycin-Resistant Enterococci: A Review of Antimicrobial Resistance Mechanisms and Perspectives of Human and Animal Health
}

\author{
Mohamed O. Ahmed ${ }^{1}$ and Keith E. Baptiste ${ }^{2}$
}

Vancomycin-resistant enterococci (VRE) are both of medical and public health importance associated with serious multidrug-resistant infections and persistent colonization. Enterococci are opportunistic environmental inhabitants with a remarkable adaptive capacity to evolve and transmit antimicrobial-resistant determinants. The VRE gene operons show distinct genetic variability and apparently continued evolution leading to a variety of antimicrobial resistance phenotypes and various environmental and livestock reservoirs for the most common van genes. Such complex diversity renders a number of important therapeutic options including "last resort antibiotics" ineffective and poses a particular challenge for clinical management. Enterococci resistance to glycopeptides and multidrug resistance warrants attention and continuous monitoring.

Keywords: vancomycin-resistant enterococcus, van operons, van genes, public health, emerging pathogen, zoonosis

\section{Introduction}

$\boldsymbol{E}$ NTEROCOCCUS SPECIES ARE natural inhabitants of the environment and an essential component of the intestinal microbiota of healthy humans and animals. ${ }^{1,2}$ To date, over 50 different enterococcal species have been described. ${ }^{3,4}$ Species most frequent within the human intestines are Enterococcus faecalis, and to a lesser extent Enterococcus faecium, whereas the most common species in various food animals are E. faecium together with Enterococcus cecorum, E. faecalis, and to some extent Enterococcus hirae. ${ }^{4-6}$ Enterococci are also opportunistic pathogens associated with serious and life-threatening infections to humans such as urinary tract infections, sepsis (blood stream infections), and endocarditis. $^{7-10}$ E. faecalis and E. faecium account for the majority of human enterococcal infections, and a leading cause of hospital-acquired and multidrug-resistant infections. 1,11,12

Enterococci became recognized as important major nosocomial pathogens due to their natural-intrinsic resistance to several antimicrobials (e.g., penicillin, ampicillin, and most cephalosporins) and capacity to quickly acquire virulence and multidrug resistance determinants. ${ }^{13-18}$ In fact, enterococci can rapidly develop resistance following the clinical introduction of antimicrobial agents, including last resort antimicrobials used to treat glycopeptide and multidrug resistance (such as quinupristin-dalfopristin, linezolid, daptomycin, and tigecycline). ${ }^{13,18-20}$
Since the first reports of vancomycin-resistant enterococci (VRE) in the $1980 \mathrm{~s},{ }^{21,22}$ epidemiological studies have demonstrated serious health and economic impacts from VREassociated infections and persistent colonization in human medicine. ${ }^{8,23-27}$ Alternatively, VRE are rare causes of infection in animals, and infrequently encountered in companion animals. ${ }^{2,28-30}$

The genetic and molecular basis of vancomycin resistance have been described with evidence that VREs may act as reservoirs and sources of other antimicrobial-resistant genes. In this article, glycopeptide and multidrug enterococcal resistance referred to by the historic term vancomycin-resistance enterococcus (VRE) and their associated clinical phenotypic/ genotypic (Genotypes and phenotypes of VREs are referred to as Van. Genes, clusters, and operons of VREs are referred to as van) characteristics are reviewed and discussed. Also, the impact of the use and past-use of certain antimicrobial agents on the evolution and emergence of VRE are discussed.

\section{Glycopeptides Resistance in Enterococci}

The main mechanism of glycopeptide resistance (e.g., vancomycin) in enterococci involves the alteration of the peptidoglycan synthesis pathway, specifically the substitution of D-Alanine-D-Alanine (D-Ala-D-Ala), to either D-AlanineD-Lactate (D-Ala-D-Lac) or D- Alanine-D-Serine (D-Ala-DSer). ${ }^{31,32}$ Such alterations can lead to variable expressions of

\footnotetext{
${ }^{1}$ Department of Microbiology and Parasitology, Faculty of Veterinary Medicine, University of Tripoli, Tripoli, Libya

${ }^{2}$ Department of Veterinary Medicine, Danish Medicines Agency, Copenhagen South, Denmark.
} 
glycopeptide resistance. For example, the respective altered D-Ala-D-Lac and D-Ala-D-Ser leads to less binding affinity of glycopeptide drugs compared to the normal cell wall precursors D-Ala-D-Ala; 1000-fold decreased binding affinity for D-Ala-D-lac and $\sim 7$-fold for D-Ala-D-Ser. ${ }^{33-35}$ The ability to induce such alterations is related to several genes harbored on mobile genetic elements and/or chromosomally encoded regions of different Enterococcus species. ${ }^{18,32}$ The latter mechanisms appear to underlie most of the vancomycin-resistant phenotypes and the variable composition of Van-related forms of resistance; this distinction may provide insights into the different levels (low-level vs. high-level) of resistance to glycopeptides. $^{34,36,37}$

\section{The van Resistance Genetic Determinants of Enterococcal spp.}

To date, operons related to vancomycin resistance for enterococci are described as van $A,-B,-C,-D,-E,-G,-L,-M$, and $N$ (Fig. 1). These are distinguishable by their degree of reduced susceptibility (i.e., resistance) to the glycopeptides, transferability, and inducibility (Table 1). ${ }^{12,18,31,32,34,37-50}$ An additional operon (vanF) has also been described but thus far only in Paenibacillus popilliae. ${ }^{51}$ This vanF variant has a high similarity to the amino acid sequences of the vanA operon, and as such $P$. popilliae has been suggested as a possible origin for vancomycin resistance in enterococci.

Most VRE outbreaks in human populations are attributed to the vanA and vanB gene clusters, ${ }^{52,53}$ both of which have also been identified in various colonized animals and environmental materials. ${ }^{54-56}$ These are complex distinct genetic determinants and the most globally widespread van-operons. ${ }^{57-60}$

The vanA operon is associated typically with transposons (Tn), such as Tn1546, involving two genes for the transposition of the element (orf1 and orf2), and one gene related to teicoplanin resistance (vanZ) (Fig. 1). ${ }^{61-63}$ The vanA gene cluster includes seven open reading frames transcribed from two separate promoters. The regulatory apparatus is encoded by the $\operatorname{van} R$ (response regulator) and vanS (sensor kinase) two-component system, which are transcribed from a common promoter, while the remaining genes are transcribed from a second promoter. ${ }^{18,31}$ Gene products that specifically modify the production of peptidoglycan precursors include $v a n H$ (dehydrogenase that converts pyruvate to lactate) and vanA (ligase that forms D-Ala-D-Llac dipeptide).

An essential part of the vancomycin resistance phenomenon is that the production of the normal D-Ala-D-Ala end of the pentapeptide does not continue. This is resolved by the vanX and van $Y$ genes where $\operatorname{van} X$ (dipeptidase that cleaves D-Ala-D-Ala) hydrolyzes and thereby interrupts the production of the pentapeptides, and vanY (D, D-carboxypeptidase) cleaves the pentapeptides that might still be produced. There can be variations in the composition of this vancomycin resistance operon due to insertion of IS elements and these variants are described as vanA-like elements.

The typical $v a n B$ operon has a similar genetic backbone to the vanA. High-level vancomycin resistance has been reported within $\operatorname{van} B$ subtypes and designated as vanB1-3

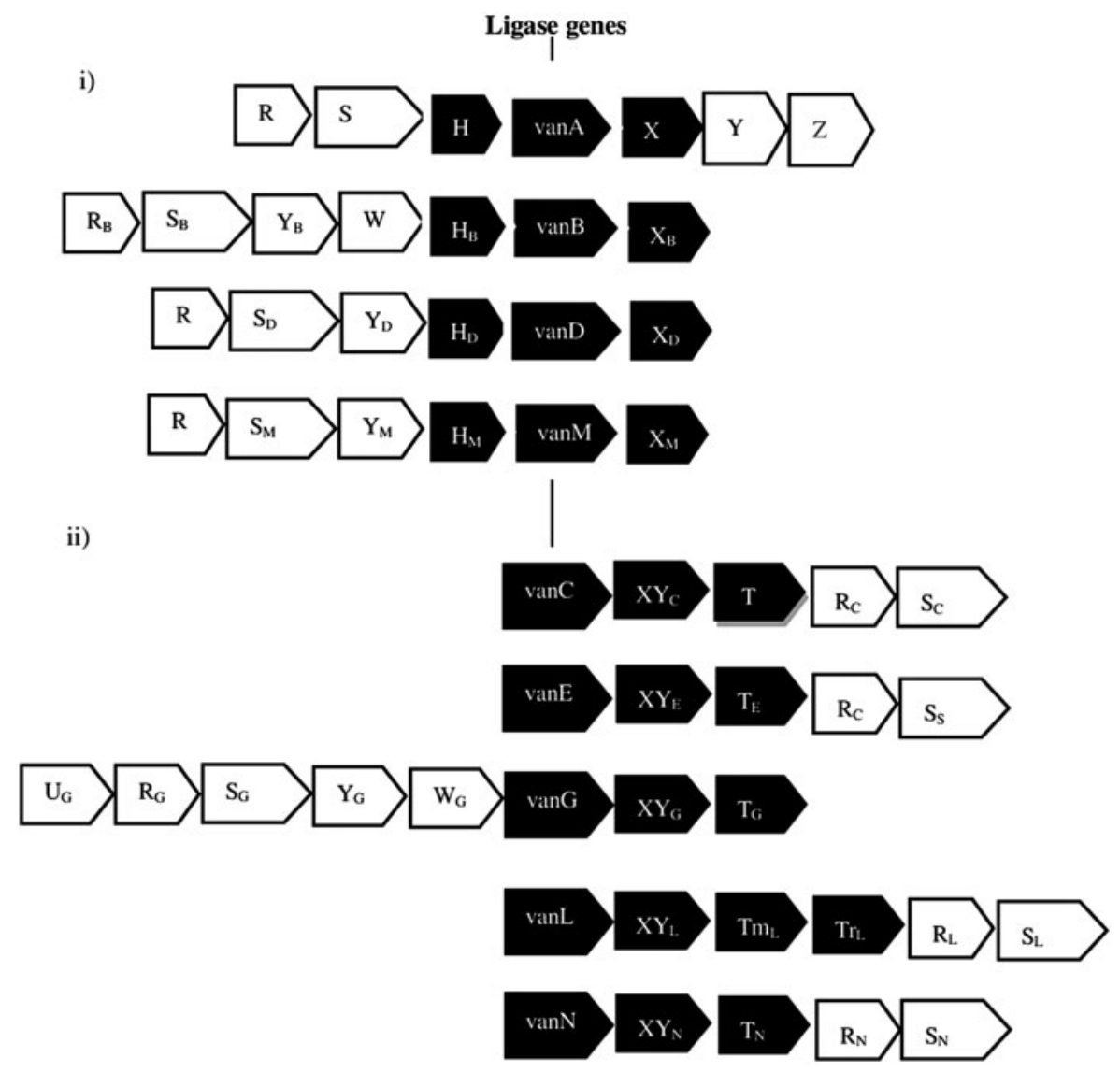

FIG. 1. Schematic diagram of van operons in Enterococci. Operons are aligned at the ligase genes and aligned according to the substitute peptidoglycan precursors as following: (i) D-Ala-D-Lac operons (A, B, D, \& M) (ii) D-Ala-DSer operons (C, E, G, L, \& N). D-Ala-D-Lac, D-Alanine-DLactate; D-Ala-D-Ser, D- AlanineD-Serine; van $U,(\mathrm{U})$ transcriptional activator; vanR, (R) response regulator; vanS, (S) sensor histidine kinase; vanW, (W) unknown function; vanH, $(\mathrm{H})$ dehydrogenase; vanT, $(\mathrm{T})$ serine racemase; $v a n T_{\mathrm{m}}$, $\left(\mathrm{T}_{\mathrm{m}}\right)$ serine racemase membrane domain; $\operatorname{van}_{\mathrm{r}},\left(\mathrm{T}_{\mathrm{r}}\right)$ serine racemase racemase domain; vanY; $(\mathrm{Y})$ carboxypeptidase; vanX, $(\mathrm{X}) \mathrm{di}-$ peptidase; vanXY, (XY) dipeptidease/carboxypeptidase; vanZ, (Z) unknown function but involved in teicoplanin resistance. $*$ Genes encode for proteins essential for expression of glycopeptides resistance (i.e., required genes for expressed VAN-resistance). 
Table 1. Summary of the Phenotypic and Genotypic Characteristics of the Alphabet VREs Operons

\begin{tabular}{|c|c|c|c|c|c|}
\hline Van-operon & $\begin{array}{l}\text { Common } \\
\text { carrier spp. }\end{array}$ & $\begin{array}{l}\text { Degree level of resistance } \\
\text { vancomycin vs. teicoplanin }\end{array}$ & $\begin{array}{l}\text { Phenotypic } \\
\text { expressions }\end{array}$ & $\begin{array}{l}\text { Location } \\
\& \text { mobility }\end{array}$ & Refs. (No) \\
\hline vanA & $\begin{array}{l}\text { E. faecium } \\
\text { E. faecalis }\end{array}$ & High for both & Inducible & $\begin{array}{l}\text { Chromosome } \\
\text { Transferable }\end{array}$ & $18,32,38$ \\
\hline vanB; vanB1, B2, B3 & $\begin{array}{l}\text { E. faecalis } \\
\text { E. faecium }\end{array}$ & $\begin{array}{l}\text { High-variable to vancomycin } \\
\text { Susceptible to teicoplanin }\end{array}$ & Inducible & $\begin{array}{l}\text { Chromosome } \\
\text { Transferable }\end{array}$ & $18,31,32,39,40$ \\
\hline vanC; vanC1, C2, C3, C4 & $\begin{array}{l}\text { E. gallinarum } \\
\text { E. casseliflavus } \\
\text { E. flavescens }\end{array}$ & $\begin{array}{l}\text { Low to vancomycin } \\
\text { Susceptible to teicoplanin }\end{array}$ & $\begin{array}{l}\text { Constitutive } \\
\text { Inducible }\end{array}$ & Chromosome & $12,34,41,42$ \\
\hline vanD; vanD1, D2, D3, D4, D5 & E. faecium & Low to high for both & $\begin{array}{l}\text { Constitutive } \\
\text { Inducible }\end{array}$ & Chromosome & $43-45$ \\
\hline vanE & E. faecalis & $\begin{array}{l}\text { Low-moderate to vancomycin } \\
\text { Susceptible to teicoplanin }\end{array}$ & Inducible & Chromosome & $32,34,46$ \\
\hline van $G ; \operatorname{van} G 1, G 2$ & E. faecalis & $\begin{array}{l}\text { Low to vancomycin } \\
\text { Susceptible to teicoplanin }\end{array}$ & Inducible & $\begin{array}{l}\text { Chromosome } \\
\text { Transferable }\end{array}$ & 47 \\
\hline $\operatorname{van} L$ & E. faecalis & $\begin{array}{l}\text { Low to vancomycin } \\
\text { Susceptible to teicoplanin }\end{array}$ & Inducible & Chromosome & 48 \\
\hline vanM & E. faecium & High for both & Inducible & $\begin{array}{l}\text { Unknown } \\
\text { Transferable }\end{array}$ & 49 \\
\hline $\operatorname{van} N$ & E. faecium & $\begin{array}{l}\text { Low to vancomycin } \\
\text { Susceptible to teicoplanin }\end{array}$ & Constitutive & $\begin{array}{l}\text { Plasmid } \\
\text { Transferable }\end{array}$ & 50 \\
\hline
\end{tabular}

VRE, vancomycin resistance enterococci.

with $v a n B-2$ as the most prevalent genotypes worldwide. ${ }^{40}$ The transfer of $v a n B$ resistance alleles occurs through the acquisition and/or exchange of transposons such as Tn1547, Tn1549, and Tn5382. ${ }^{38,64,65}$ The conjugative vanB transposon, known as Tn1549 is widely prevalent among VanBtype enterococci and other gram-positive bacteria. ${ }^{66}$ This is mainly a chromosomal transposon and less frequently found on plasmids. ${ }^{67,68}$

The genetic organization of $v a n B$ is similar to that of $v a n A$, in that it contains two distinct promoters transcribing seven open reading frames, but there are some important differences (Fig. 1). For example, vanB encodes a two-component signaling system (named $v a n R_{B}$ and $v a n S_{B}$ ) that is considerably different from that encoded in vanA. Furthermore, vanB encodes homologs of $v a n H$ and the D-Ala-D-Ala ligase (encoded by $v a n B$ ), and the peptidases (vanX and vanY). However, vanB lacks a homolog of $v a n Z$, and instead encodes a protein named van $W$, whose role in resistance is not fully understood. ${ }^{18}$

In contrast, the van $C$ operon is genetically different from $v a n A$ and $v a n B$, and typically "less virulent" enterococci than those carrying inducible $v a n A$ and $v a n B$ gene clusters. $^{34,41,42}$ The van $C$-resistant subtypes, van $C-1$, van $C$ - 2 , and vanC-3, are known to be intrinsically present in Enterococcus gallinarum, Enterococcus casseliflavus, and Enterococcus flavescens, respectively, ${ }^{12}$ and sometimes seen as markers for these enterococcal species. The vanC-2 gene cluster in $E$. casseliflavus demonstrates a composition similar to the vanC1 cluster in E. gallinarum. ${ }^{32,42}$ More recently, a vanC-4 subtype was also described with 93-95\% nucleotide homology with vanC-2/-3. ${ }^{41}$

The vanD operons are exclusively chromosomal and similar to vanA and vanB. ${ }^{43-45,69-72}$ This operon represents a number of different combinations of mutations and furthermore, different enterococcal strains demonstrate a constitutive resistance phenotype resulting from different mutations within the operon regulators. These various modifications have led to a wide range of subtypes and resistance phenotypes. ${ }^{73}$ Nevertheless, the vanD is described sparsely among various enterococci species, and can also be carried by the vanC E. gallinarum. ${ }^{74}$

The vanE gene cluster has been described in a few $E$. faecalis strains from North America and Australia. ${ }^{46,75,76}$ The vanE cluster resembles the vanC1, which occurs naturally in E. gallinarum (Fig. 1). Studies have suggested that a cluster within an integrase gene of the vanE-E. faecalis may have evolved with the acquisition of this operon; however, reports have not determined the transfer-ability of this gene cluster. ${ }^{75}$ Enterococcus faecalis possessing a vanG cluster have been described and two subtypes were identified. ${ }^{47,77,78}$ In contrast to the other van D-Ala-D-Ser operons (i.e., vanE, vanC vanL and $\operatorname{van} N$ ), this operon has been shown to be transferable via a conjugative plasmid from $E$. faecalis.

The set of van genes was expanded recently after the discovery of vanL, vanM, and vanN operons. The vanM is genetically and phenotypically similar to $\operatorname{van} A, \operatorname{van} B$, and vanD, whereas both vanL and vanN are similar to vanC (Fig. 1). The vanL gene cluster exhibits $49-51 \%$ sequence identity to the vanE and vanC ligases. However, this VRE E. faecalis isolate did not demonstrate either a transfer or conjugation ability, suggesting that the vanL gene cluster is chromosomally encoded. ${ }^{48}$ The vanM operon has been described in E. faecium VRE isolates and demonstrated a close gene arrangement to vanD and in vitro transferable resistance by conjugation. ${ }^{49}$ The vanN operon is the most recently identified gene cluster described in E. faecium. ${ }^{50}$ This is a similar operon to $v a n G$, but more unique since it has also been reported to be transferable via mobile genetic elements, and only in E. faecium. In general, the D-AlaD-Ser operons are frequently chromosomally encoded but some of the latest added operons (i.e., $\mathrm{G}$ and $\mathrm{N}$ ) are transferable in E. faecalis and E. faecium respectively, and only exceptionally. 


\section{Phenotype Versus Genotype Expression of Vancomycin Resistance in Clinical Enterococcal Species}

VRE phenotypes are defined by the expression of vancomycin-related resistance and virulence factors, regardless of the genes expressed but mainly related to their clinical characteristics. ${ }^{79}$ The VanA and VanB phenotypes, and most recently the VanC, appear to be clinically the most important, and capable of conferring high-levels of resistance to vancomycin and teicoplanin; however, the VanA phenotype appears remarkably more virulent.

Motile enterococci, such as E. gallinarum, E. casseliflavus deserve special mention in phenotype designations, since the VanC phenotypes were previously less frequent causes of human clinical infections and confer a low-level of resistance to vancomycin, but not to teicoplanin. ${ }^{12,14}$ While the global incidence of VanC phenotypes remains relatively low, including a lower risk of mortality compared to VanA and $\mathrm{VanB},{ }^{80}$ there has been a rise in VanC-type outbreaks reported in humans. ${ }^{81-85}$ For example, several human bacteremia cases have been identified as hospital-acquired VRE-C-type $E$. gallinarum and E. casseliflavus infections, of which a few cases failed to respond to therapeutic interventions with fatal consequences. ${ }^{84}$ Moreover, a study involving 13 Greek human hospitals demonstrated that the VanC phenotype (i.e., $\mathrm{C} 1, \mathrm{C} 2$, and C3) was the most prevalent, representing 57\% of VRE isolates followed respectively by VanA and VanB phenotypes. ${ }^{86}$ A Swiss study identified the VanC genotype in $98 \%$ of 296 clinical VRE strains isolated from patients of which 290/ 296 VRE isolates were of fecal origin. ${ }^{87}$ This is in contrast to the USA, where the VanC genotype is very rare compared to the dominant VanA and VanB genotypes. In addition, recent reports from other regions such as North Africa have revealed a low prevalence of clinical VanC enterococci in comparison to VanA type. ${ }^{88}$

The VanC phenotype is known to be constitutively expressed; however, E. casseliflavus and E. gallinarum have been reported to harbor inducible resistance types as well. ${ }^{89}$ Furthermore, E. gallinarum/casseliflavus have been found to carry other van gene clusters (i.e., vanA, vanB and vanD) and express high-level vancomycin resistance. ${ }^{90-94}$ VanC $E$. gallinarum have been detected in clinical isolates from humans and farm animals, carrying vanC-1 and vanA genes, and showing a high-level of resistance to glycopeptides and linezolid. ${ }^{81,82,92,95-98}$ E. gallinarum can capture the genetic determinants of high-level glycopeptide resistance and transfer these determinants to other enterococci (i.e., E. faecium). ${ }^{90,93,99}$ The emergence of high-level resistance to glycopeptides among less common motile enterococci, mainly E. gallinarum, suggests a need for increased awareness for detection and proper characterization of these microorganisms. ${ }^{100,101}$

\section{Geno-Geographic Characteristics of the VRE and Enterococcal Clones}

Both E. faecium and E. faecalis are distinct among enterococci and recognized as a major reservoir of acquired glycopeptide and multidrug-resistance (MDR) by carrying the most common reported van genes. ${ }^{1,8}$ A systematic review and meta-analysis involving Iran and few European countries revealed a close rate of prevalence between countries of VRE infections in humans and ranges between
8-13\%, largely from E. faecalis carriers. ${ }^{102}$ Whereas in the USA, E. faecium is the carrier of $95 \%$ of recovered VRE isolates ${ }^{103}$ and the main clinical reservoir of the VanA and VanB genotypes in Europe, Northern and Latin America, and Southeast Asia. ${ }^{14,52,53,63,104}$ Alternatively, E. faecalis has been frequently associated with $v a n G, L$ and $E$ genes (Table 1). The other van genes remain sparsely reported and neither responsible for most VRE clinical infections nor outbreaks in human medicine.

The VanA genotype is the most common among the reported E. faecium and E. faecalis isolates worldwide from humans and animals but less frequently reported in other enterococci species such as E. gallinarum, Enterococcus hira, and Enterococcus durans. ${ }^{18,105}$ For instance, a recent Iranian study describing a collection of 160 clinical enterococci reported the rate of VRE strains at $19 \%$, largely E. faecium species dominantly carrying vanA genes. ${ }^{104}$

On the other hand, the VanB genotype is reported more frequently in fewer countries such as Australia, Sweden, and Germany. ${ }^{106-108}$ Such variability in genotypes has been attributed to the different antimicrobial use patterns between different countries. For example, in Australia the VanBVRE is the dominant E. faecium from human cases, but has neither been found in animals nor frequently in normal human feces. ${ }^{109}$ However, indistinguishable vanB elements have been found in anaerobic commensal bacteria from human faeces, and might be a source of VanB resistance to enterococci. ${ }^{110}$ In addition, vanB genetic determinants have been detected in VanC enterococcal species, ${ }^{111}$ and vanC genes in E. faecalis and E. faecium from human infections. $^{36,112-114}$ This supports the argument that glycopeptides resistance cannot be predicted only by the VRE genotype, particularly the motile species. ${ }^{100}$

Elucidating further about VRE and enterococcal clinical outbreaks requires different molecular techniques to assess patterns and clonality of genomic DNA as well as subspecies phylogenetic relationships of enterococci. The application of such methods in recent years (i.e., amplified fragment length polymorphism, restriction endonuclease analysis, CRISPR analysis, multi-locus sequence typing (MLST) and whole genome datasets have separated $E$. faecium into two major clades designated as clades A and B. ${ }^{11,115-121}$ Clade A are mostly of clinical origin and associated with human-hospital infections and further divide into two subtypes: clade A1, which include epidemic hospital strains, and clade A2, which include animal and sporadic human infections. Whereas, clade B strains are of nonclinical origin and associated with community. ${ }^{117,120,122}$

The genome of clade A1 are characterized by harboring a greater abundance of virulence and antibiotic resistance genes compared to non-A1 lineages. ${ }^{4}$ Clade A1 or clonal complex E. faecium 17 (CC17, a MLST designation) is a global polyclonal cluster of hospital adapted clones with the potential to cause invasive disease and adapted to the hospital environment and GIT colonization. This clone contains the well characterized global sequence type (ST) 17 and the descendant variants; ST16, ST78, ST63, ST64, and ST174. ${ }^{122}$ The global clonal complex E. faecium $\mathrm{CC} 17$ is frequently characterized as multidrug resistant, including vancomycin, and typically carrying specific virulent gene markers, especially the hyaluronidase gene (hyl) and the 
enterococcal surface protein encoding gene (esp), as well as the IS16 insertion-element. These elements characterize CC17 clonal strains and associated with hospital acquired and MDR enterococcal infections. ${ }^{88}$ Alternatively, E. faecalis are less restricted and some clones such as CC2, CC40, and CC87 are shared between hospitals and the community.

The global increase in MDR Enterococcus faecium strains has been linked to the emergence of lineage 78. Isolates belonging to sequence type 117 (ST117) within the lineage 78 are increasingly identified from clinical isolates in many European health institutions. ${ }^{123}$ Other countries such as Australia have experienced the emergence of new and rapid spread of $E$. faecium clones within the clade A1 lineage replacing the common ST17 type by the ST203 type as the main cause of blood stream infections and a rising proportion of $v a n B$ VRE. ${ }^{120}$ Genomic analysis of these particular new emergent clones revealed 40 unique genes including Tn1549 indicating a rapid change in the epidemiology and genomics of VRE in this country.

Genomic and epidemiological investigations of VRE are sparse from the under-developed regions, such as North African. Recent studies from such regions have reported novel information. For instance, a study from Tunisia has documented the prevalence of VanA - E. faecium from clinical and hospital sources at 5\%, carrying purK and esp gene, and the IS16 element, but without the hyl gene. ${ }^{88}$ Furthermore, e-BURST analysis of these strains has identified a new emergent clone ST910 as the dominant type and not belonging to the global $\mathrm{CC} 17$, suggesting a rapid evolution in this country. ${ }^{88}$

A previous study from this North African country reported frequent sequence types ST18 and ST80 belonging to CC17 among clinical vanA E. faecium, all carrying the IS16 element, but lacking $h y l$ and esp genes. ${ }^{124}$ Similar variability was also reported from a Brazilian study describing VRE-E. faecium strains from colonized hospital patients showing ST412 as the most shared, belonging to CC17, harboring the IS16, Tn1546, esp, and $a c m$ genes, but lacking the hyl gene. ${ }^{125}$ These results contrast previous reports from Brazil and suggesting interspecies horizontal transfer of genetic and resistant elements between the enterococci. ${ }^{125}$

Global VRE and VSE isolates, both from human (i.e., hospital and community-acquired) and nonhuman (i.e., environment and animals) sources have revealed that hospital enterococcal isolates are related closely to/or descending from the MLST single clonal-complex (CC), CC17. ${ }^{23,126}$ Further analysis of E. faecium demonstrated that the major hospital clones ST78 and its single locus variants ST192 and ST203 group belong in a different BAPS group than ST17 and ST18. ${ }^{115,127,128}$ This indicates that hospital-associated E. faecium have not recently evolved from a single ancestor and consequently the designation of $\mathrm{CC} 17$ as a hospitalselected clonal complex may not be entirely accurate.

Also, the highly prevalent E. faecium hospital clones are almost absent in the community, ${ }^{129}$ but this is not the case for E. faecalis. Based on MLST, there are seven most prevalent $E$. faecalis clones among clinical and outbreakassociated isolates $(n=355)$, including ST6, ST9, ST16, ST21, ST28, ST40, and ST87, accounting for only $37 \%$ of the hospital-derived isolates (http://efaecalis.mlst.net/). ${ }^{130}$ These are found frequently in the community, farm animals and food products while the major hospital-derived $E$. faecium clones are found rarely in the community $(8 \%$ of 513 nonhospital isolates). ${ }^{30,131,132}$

The complete genomic sequence of E. faecium was completed in 2012 and in-depth studies analyzing the genomics of the significant enterococci are still relatively small. ${ }^{133}$ Most recent molecular epidemiological studies and genomic analysis using WGS have revealed discriminating information about the genomic characteristic and elements of enterococci involved in virulence and antimicrobial resistance. ${ }^{121}$ However, knowledge is still incomplete, where future prospective analysis should rely on combining the current and future genomic insights with the subsequent functional and phenotypic change of the pathogen population and dynamics.

\section{Insights into Animal-Associated VRE and Public Health Issues}

Previously, the emergence of VREs in food-animal production systems has been largely attributed to the widespread use of sub-therapeutic avoparcin (a glycopeptide for animal use) for growth-promotion throughout Europe and other countries in the mid-1990 s. ${ }^{134-141}$ In fact, the isolation of different VRE genotypes, particularly VanA-VRE, from the community, animal faeces, sewage and raw meats, suggested that VREs colonized and spread as a result of the use of animal growth promoters (esp. avoparcin) and not human hospital-use alone. ${ }^{57,142-144}$

On the contrary, other countries like Canada and United States have never approved avoparcin and not reported VRE in animals until 2008. ${ }^{18,37}$ In North America, VREs are one of the major hospital acquired infections attributed largely to the clinical use of vancomycin in humans. ${ }^{145,146}$ In addition, the unique epidemiological distribution of VREs in Australia has been attributed to the combination of extensive use of vancomycin in humans and avoparcin as a growth promotor in the animal industry. 4,147

Avoparcin, as a growth promoter, was banned in the EU in 1997 as detailed in the Commission Directive 97/6/EC. Despite the subsequent reduction of VRE prevalence from animalderived products and fecal samples of humans, ${ }^{148}$ VRE-related human infections and outbreaks have increased in the EU since $1999^{149-154}$ as well as the prevalence of VRE in asymptomatic human carriers in Europe. ${ }^{155,156}$ While the ban of antimicrobial growth promoters likely played an important role in reducing VRE carriers in animals, and in some cases a remarkable decrease in the incidence of VREs and glycopeptide-resistant Enterococcus species, the consequences of such previous livestock practices may not be reversible. ${ }^{143,148,157}$

In Norway, VREs were still easily found (96-98\% proportion of positive samples) from poultry farms exposed previously to avoparcin after more than a year and a half after the ban, whereas none were isolated from the unexposed poultry and swine farms. ${ }^{158}$ Moreover, 3 years after the ban of avoparcin, VRE were isolated from previously exposed and unexposed poultry farms (99\% and $11 \%$ of the respective grouped-studies farms) as well as from farmers (18\% and $1 \%$ from farmer samples from exposed and unexposed farms). ${ }^{159,160}$ Recent data from Europe revealed that VRE-VanA genotypes were detected in Danish poultry production 15 years after the ban of avoparcin and found in $47 \%$ of fecal samples with variable resistant phenotypes and 
diverse E. faecium clones. ${ }^{161}$ In Italy and Germany, the frequency has been reduced, however, VREs can still be recovered from different farm animals, poultry meat and pork products, and fecal samples of healthy persons, ${ }^{148}$ including clonally related vanA VREs. ${ }^{105}$ Similar results have also been reported in Taiwan, where a ban of avoparcin in year 2000 resulted in a notable decreased VRE prevalence in chicken but persisted in the same populations. ${ }^{162}$

Prior to the European avoparcin ban, high rates of VRE carriage were also reported in dogs. ${ }^{163}$ A subsequent Dutch study, performed 5 years after the avoparcin ban, reported no VRE in a 100 dogs samples. ${ }^{164}$ Other studies have found that healthy dogs and cats can be colonized by VRE. ${ }^{165-167}$ In addition, VRE isolates from dogs demonstrate similar genetic lineages to hospital-acquired infections in humans. ${ }^{168-170}$ Furthermore, VRE carrying vanA have been described in healthy horses in Italy, Poland, and Hungary. ${ }^{171}$

When VRE contaminated meat was found in retail outlets as well as the fecal flora of humans, in countries with a heavy use of avoparcin, ${ }^{172,173}$ it was quickly concluded that the case against growth-promoting antibiotics, especially avoparcin, was proven. ${ }^{157,174,175}$ However, experiences gained after the ban have revealed some doubts as to the route of possible transmission of VRE determinants between animals and humans. For example, despite higher VRE carrier frequencies in animals in Europe, nosocomial VRE infections in humans were lower in Europe than in the United States ${ }^{176}$ even though avoparcin was never used in animals in North America.

Initial reports from 10 to 20 years ago indicated that it has been difficult to prove a food-borne infection route to humans directly and the few examples published of identical VREs between humans and animals resulted from direct animal contact, rather than meat consumption. ${ }^{173}$ Experimental infection of humans with animal VRE strains resulted in transient colonization only. ${ }^{177,178}$ Nevertheless, evidence obtained by using different molecular typing techniques, indicates strong correlations between VREs or genetic determinants in animals and humans (Table 2). ${ }^{23,65,130,131,166,177-199}$ These correlations between animal and human VRE carriage does not necessarily demonstrate causality, but that several reservoirs exist, including wild animals and plants. ${ }^{200}$

Alternative theories have been proposed to explain VRE persistence among food producing animals, despite the avoparcin ban. ${ }^{161}$ In Denmark, the use of the macrolide, tylosin, in pigs was suggested to co-select for VREs since the genes encoding the two resistances are located on the same plasmid. ${ }^{201,202}$ For example, in vitro studies have shown that ermB and vanA genes were located on the same transferable DNA elements, most likely large plasmids. A similar coselection for VRE persistence has been proposed via tetracycline resistance coded by the tet $(\mathrm{M})$, but transferability has not been easily demonstrated. ${ }^{135,201}$ Also, a conjugative plasmid conferring acquired copper resistance, via the $\operatorname{tcr} B$ gene, has been shown to be strongly correlated with macrolide $[\operatorname{erm}(\mathrm{B})]$ and glycopeptide resistance (vanA) genes in Enterococcus faecium isolates from pigs, whereby all genes can share the same conjugative plasmid. ${ }^{143,204}$

Another theory is that the plasmid addiction systems located on the same plasmid as the vanA gene would force the bacteria to retain the resistance. ${ }^{204}$ Essentially, the plasmid addiction system is the strict natural selection of plasmid- encoded gene(s) that is required for the viability of the bacterium. $^{205}$

Nosocomial human-related VREs tend to be more clonal populations persisting in hospitals, and related to human consumption of antimicrobials or hospital environments. ${ }^{101,206}$ What appears to be important differences between the VRE subpopulations are other factors that determine spread and virulence. For instance, screening admitted patients for colonized VRE has significantly reduced nosocomial VRE outbreaks and distinguished the community-acquired VRE cases. $^{206}$

In addition, epidemic hospital-acquired strains of vancomycin-resistant E. faecium from the USA, Europe, and Australia often have certain virulence genes, $e^{207}{ }^{207}$ and $h y l$ genes, ${ }^{208}$ which are not found in nonepidemic or animal isolates, food or sewage. ${ }^{209}$ These genes, are part of a putative pathogenicity island and considered to be a marker for nosocomial-epidemicity that contributes to the acquisition of antimicrobial resistant genes and spread of vancomycinresistant E. faecium isolates in hospitals. ${ }^{210}$ Thus, the administration of glycopeptides for humans and previous use as feed additive growth promoters in animals are important factors in the emergence of vancomycin resistance in enterococci, ${ }^{103,147}$ but other virulence factors appear necessary before these subpopulations are represented in human clinical infections. ${ }^{211}$

Since year 2000, VRE rates in human clinical isolates have increased in numerous European countries despite glycopeptide resistance declining in nonhospital reservoirs. ${ }^{212}$ The acquisition of vancomycin resistance by a distinct subpopulation of hospital-acquired ampicillin-resistant E. faecium strains has been the main factor responsible for the spread and dissemination. Clones belonging to the CC17 lineage are frequently characterized by ampicillin and fluoroquinolone resistance, and harboring the putative virulence genes esp and hyl. ${ }^{23,213-215}$ As late as 2016, there was a notable increase hospitalized human patients with VRE infections in Danish hospitals (DANMAP, 2016), mostly due to vanA E. faecium. In Europe, new reports of VRE are still being reported (e.g., West Balkan regions), as Enterococcus faecalis and E. faecium, both as VanA and VanB phenotypes. ${ }^{216}$

It is possible that a proportion of European human hospitalized VRE cases stem from environmental or food sources either through bacterial contamination or indirectly, via gene transfer. ${ }^{217,218}$ This may in-part explain the different VRE subpopulations with variable levels of virulence associated with human clinical infections. For example, molecular typing of clinical VRE isolates from European hospitalized patients tend to be heterogeneous with respect to their genotypic fingerprints, ${ }^{176,207}$ whereas in the USA homogeneity is more common. ${ }^{219}$ Other human VRE subpopulations have emerged, either as community-acquired VRE that are frequently susceptible to amoxicillin or gentamicin, or nosocomial VRE, which in contrast are also resistant to amoxicillin/gentamicin. ${ }^{220}$

\section{Emergence of MDR Among Enterococcus spp.}

The emergence of multidrug resistant enterococci to the newer drugs including last resort antibiotics is worrisome and of global concern (www.who.int/mediacentre/news/ releases/2017/bacteria-antibiotics-needed/en). These have variable susceptibility to even less antimicrobial agents 
Table 2. Summary of the Evidence of Links Between VRE or Enterococcal spP. of Animal Origin Versus Human Origin Isolates

\begin{tabular}{|c|c|c|c|}
\hline Molecular study & Unit of comparison & Results & Refs. (No.) \\
\hline Cohort study & E. faecium & $\begin{array}{l}\text { Transient colonization with } E \text {. faecium of animal origin } \\
\text { can persist within the intestines of healthy humans not } \\
\text { receiving antimicrobial agents for between } 4 \text { to } 30 \text { days. }\end{array}$ & 177,178 \\
\hline PFGE & $\begin{array}{l}\text { E. faecium (Animal } \\
\text { vs. human origin) }\end{array}$ & $\begin{array}{l}\text { Similar to highly similar VRE PFGE profiles (Animal } \\
\text { isolates vs. Human) }\end{array}$ & 179,180 \\
\hline AFLP & $\begin{array}{l}\text { E. faecium (Animal } \\
\text { vs. Human origin) }\end{array}$ & $\begin{array}{l}\text { Different VRE strains from hospitalized versus } \\
\text { nonhospitalized human strains. } \\
\text { Hospitalized human VRE strains were similar to dogs, cats, } \\
\text { and some veal calves. Nonhospitalized human VRE } \\
\text { strains were similar to pigs. }\end{array}$ & 181 \\
\hline MLST & $\begin{array}{l}\text { E. faecium (Animal } \\
\text { vs. Human origin) }\end{array}$ & $\begin{array}{l}\text { Initial reports of VRE (E. faecium) strains were host-specific; } \\
\text { for example, hospitalized humans VREs clustered in clonal } \\
\text { complex (CC) } 17 \text {, whereas animal E. faecium isolates } \\
\text { belonged to other sequence types and clonal clusters. }\end{array}$ & 23,182 \\
\hline MLST & $\begin{array}{l}\text { E. faecium animal } \\
\text { isolates }\end{array}$ & $\begin{array}{l}\text { Dogs can be a reservoir of VRE (E. faecium) belonging } \\
\text { to STs (e.g., ST17) related to human clinical infections. } \\
\text { Pig: found CC17: ST132 (part of CC17) } \\
\text { Chicken meat: found vanB2 ST17 E. faecium } \\
\text { Rabbit meat: found vanA ST78 E. faecium } \\
\text { Pig: vanA E. faecium isolates CC5 common to pigs and } \\
\text { found in human urinary tract infections and fecal samples } \\
\text { from nonhospitalized humans. }\end{array}$ & $65,166,183-185$ \\
\hline MLST & $\begin{array}{l}\text { E. faecalis (Animal } \\
\text { vs. Human origin) }\end{array}$ & $\begin{array}{l}\text { Hospitals outbreaks related to MLST clonal complexes } \\
\text { (CC2, CC } 9 \text {, and CC87). CC2 (ST6) also detected in pigs. }\end{array}$ & 131,186 \\
\hline MLST and PFGE & E. faecalis & $\begin{array}{l}\text { ST16 E. faecalis isolates have been detected in pigs, poultry, } \\
\text { healthy humans, and hospitalized patients with endocarditis. } \\
\text { ST116 was found in vanA E. faecalis ST116 isolates found in } \\
\text { turkey meat, nonhospitalized humans, and a patient. } \\
\text { E. faecalis isolates of ST40 and ST97 detected in pigs and } \\
\text { endocarditis patients. }\end{array}$ & $130,131,186-190$ \\
\hline PCR, sequencing & E. faecium & $\begin{array}{l}\text { Indistinguishable variants of } \mathrm{Tn} 1546 \text { transposons found in } \\
\text { isolates of human and nonhuman origin. } \\
\text { Point mutation in vanX (G to T) at position } 8234 \text { in } \mathrm{Tn} 1546 \text {, } \\
\text { specifies VREs of pig origin (e.g., T mutation), and } \\
\text { poultry origin (e.g., G mutation). Both types were found } \\
\text { among human E. faecium isolates. }\end{array}$ & $191-195$ \\
\hline $\begin{array}{l}\text { Gene transfer } \\
\text { experiment, with } \\
\text { gnotobiotic } \\
\text { mice/rats. }\end{array}$ & E. faecium & $\begin{array}{l}\text { High frequency transfer of vanA from animal origin } \\
\text { E. faecium to human origin E. faecium. } \\
\text { vanA of chicken origin was transferred to a CC17 recipient } \\
\text { (obtained from a patient with sepsis) within the intestines } \\
\text { of cephalosporin-treated mice. }\end{array}$ & 196-198 \\
\hline $\begin{array}{l}\text { In vivo conjugation } \\
\text { experiment }\end{array}$ & E. faecium & $\begin{array}{l}\text { Transfer of vanA from an E. faecium isolate of animal origin } \\
\text { to an E. faecium isolate of human origin (non-CC17 type) } \\
\text { within the intestines of healthy human volunteers. }\end{array}$ & 199 \\
\hline
\end{tabular}

VRE, vancomycin-resistant enterococci; PFGE, pulsed field gel electrophoresis; AFLP, amplified-fragment length polymorphism; MLST, multilocus sequence typing; PCR, polymerase chain reaction; CC, clonal complex; ST, sequence type.

and increasingly associated with significant morbidity and mortalities in human medicine. The concern is further complicated by the genetic intra-ability of enterococci to exchange resistance determinants and/or transfer to other Gram-positive organisms such as staphylococci and streptococci. $^{221}$ Generally, oxazolidinone-linezolid, daptomycin, quinupristin/dalfopristin (QD), and tigecycline are invaluable antibiotics frequently used to treat serious infections and therapeutic complications caused by multidrug resistant enterococcal infections, VRE and MRSA. ${ }^{222,223}$

Linezolid, daptomycin, and tigecycline have been increasingly utilized over the past decade as last-line therapeutics, to combat MDR enterococci and staphylococci, however, clinical isolates with reduced susceptibility have emerged. ${ }^{221,224-226}$ Oxazolidinone-linezolid was approved in 2000 and widely used, but the emergence of resistance is reportedly associated with its therapeutic and extended applications for VRE as well as vancomycin-susceptible enterococci cases. Linezolid-resistant enterococci (LRE) is of greater concern and increasingly encountered over the past decade although at a low prevalence of less than $1 \%$ among the enterococci and staphylococci. ${ }^{223,225}$ However, new generation oxazolidinones (i.e., Tedizolid phosphate) has been recently approved, which demonstrated better efficacy against clinical MDR Gram-positive pathogens such as MRSA, VRE, and LRE. ${ }^{225}$ 
Resistance (or reduced susceptibility) to the oxazolidinonelinezolid is frequently reported to be mediated either by acquisition of the chloramphenicol-florfenicol resistance ( $c f r$ ) gene or point mutations within the ribosomal complex system (23S rDNA or ribosomal protein genes). ${ }^{225}$ Linezolid resistance is also linked to optrA gene, which recently was described in humans, food producing animals and products, from various global regions (i.e., China and Denmark). ${ }^{218}$ Acquisition of the $c f r$ gene is often carried on transferrable mobile genetic determinants, associated with resistant infections in livestock and reduced susceptibility to a broad range of drugs (i.e., Phenicols, Lincosamides, Oxazolidinones, Pleuromutilins, and Streptogramin A). Furthermore, a study from Germany has recently documented a $c f r$ like-gene named $c f r$ (B) variant gene locus in clinical strains of $E$. faecium with $99.9 \%$ identical sequence to a $c f r$-like gene from Clostridium difficile. ${ }^{223}$ This new variant gene was found on both mobile and/or extra-chromosomal DNA. Recently, E. faecium was reported from food producing animals harboring a novel plasmid coding for multidrug resistance, including Linezolid. ${ }^{227}$

In addition, tigecycline-resistant E. faecium is also emerging, but the precise mechanism is unclear. A recent genomic analysis of clinical enterococci expressing tigecycline-resistant revealed tetracycline-resistant determinants; tet(L)- encoded efflux pumps and tet(M)-encoded ribosomal protein in the expression of such resistance. ${ }^{226}$ Another recent German investigation analyzing the spread of Tn1549-vanB-genotype resistance revealed the dissemination was attributed to the exchange of large chromosomal fragments between positive and negative $v a n B$ enterococci isolates thus providing a better understanding of the spread of multidrug-resistant pathogens. ${ }^{108}$

In summary, VRE and enterococcal MDR infections are increasingly reported from humans with distinct geographic differences. The vanA-VRE are more commonly associated with poultry than other food animals (e.g., cattle, swine), with some geographic differences. On the other hand, VanC and VanN-VRE phenotypes have been detected frequently from farm and companion animals as well as meat products destined for human consumption (i.e., chicken, pigs, cow, and horses). ${ }^{228-230}$ Other reports have also shown the unusual presence of different van genes in E. casseliflavus isolated from farm animals. ${ }^{231}$ Thus, animal microflora may play an important role in the development and emergence of novel and evolved geno/phenotypes of glycopeptide and multidrug resistances in different enterococcal strains as well as other bacterial strains. ${ }^{232,233}$ Nevertheless, the zoonotic risk of different resistant organisms including VREs from farms and livestock has not been fully defined. ${ }^{234}$

Enterococci of foodborne origin are not known as a direct source of resistant enterococci in humans, but could pose a risk to transfer resistance determinants (e.g., van genes) to human-adapted enterococcal strains. For example, human colonization by VRE of animal origin has been documented including trans-conjugant transfer of van genes between enterococcal species within the human intestinal microflora. ${ }^{199,235,236}$ Also, the documentation of in vitro interspecies conjugal transfer of vancomycin resistance and MDR enterococcal phenotypes of environmental origin indicates the potential risk of these sources as well as the diverse ability to transfer such resistance determinants to human path- ogens. ${ }^{237}$ Antimicrobial-resistant E. faecalis and E. faecium of animal origin have demonstrated the ability to acquire resistance genes and act as donors of such genes. ${ }^{238,239}$ Such complex genetic exchanges and acquisitions might explain the continuing emergence and evolution of enterococcal antimicrobial resistance.

\section{Conclusions and Prospective Challenges}

Enterococcus species colonize and survive in widely different hosts and conditions. As part of the healthy intestinal flora and environment, enterococci are part of the cycle of continuous exposure to prophylactic/metaphylactic and therapeutic antimicrobial agents in human and animal hosts, which has likely contributed to their ability to acquire and develop unique profiles of virulence and antimicrobial resistance.

In contrast to vancomycin-resistant E. faecalis and E. faecium, other species such as E. casseliflavus or E. gallinarum have attracted less attention, despite associations with environmental and livestock sources as well as human infections and outbreaks. This suggests a need for continuous monitoring of a broader range of enterococcal species as well as other vancomycin-resistant genes (e.g., VanC genotypes).

The role of animals and food products in the human VRE population dynamics needs to be further defined. While many aspects of VRE are well known to human and public health, both veterinary and agricultural awareness of these ongoing issues is sparse. It may have been a premature conclusion that the animal involvement of VRE issues was resolved after the ban of avoparcin. The collection of evidence suggests that animal-associated vancomycinresistant E. faecalis and E. faecium as direct sources of human infections is unlikely. The role of animal-associated vancomycin-resistant E. casseliflavus, E. gallinarum and others needs to be further defined.

Food animals can be reservoirs of van genes of clinical importance to human-related infections (e.g., vanA, vanC), including novel van genes. Further detailed sequencing of animal-associated van genes compared to clinical human VRE isolates could help to better define the significance of animal reservoirs. Transient colonisation of animalassociated VRE can lead to the transfer of van genes to human adapted enterococci strains with relevant virulence factors. The amplication of animal VRE reservoirs can be related to antimicrobial use patterns, as demonstrated by the previous massive consumption of avoparcin, with major spillover effects on human populations.

Persistence of van genes in animal populations has proven to be more challenging to resolve than previously thought. The potential co-selection of VREs in animals based on other antimicrobial consumptions (e.g., macrolides, tetracyclines) is worthy of further investigations. In contrast to humans, VRE infections in animals are rare, and infrequently seen in companion animals. Given the importance of animal reservoirs then VRE screening should be part of national antimicrobial resistance surveillance systems for indicator bacteria. Since the ban on avoparcin, veterinary medicine has demonstrated that the needs of animal health can be served without glycopeptide antimicrobials. As such, the class of glycopeptide antimicrobials should be reserved for human medicine. 


\section{Disclosure Statement}

None of the authors of this article has a financial or personal relationship with other people or organizations that could inappropriately influence or bias the content of the article.

\section{References}

1. van, S.W., and R.J. Willems. 2010. Genome-based insights into the evolution of enterococci. Clin. Microbiol. Infect. 16:527-532.

2. Boehm, A.B., and L.M. Sassoubre. 2014. Enterococci as indicators of environmental fecal contamination. In M. S. Gilmore, D. B. Clewell, Y. Ike, and N. Shankar (eds.), Enterococci: From Commensals to Leading Causes of Drug Resistant Infection. Boston, Massachusetts Eye and Ear Infirmary.

3. Bonacina, J., N. Suarez, R. Hormigo, S. Fadda, M. Lechner, and L. Saavedra. 2017. A genomic view of food-related and probiotic Enterococcus strains. DNA Res. 24:11-24.

4. Guzman Prieto, A.M., S.W. van, M.R. Rogers, T.M. Coque, F. Baquero, J. Corander, and R.J. Willems. 2016. Global emergence and dissemination of enterococci as nosocomial pathogens: attack of the clones? Front. Microbiol. 7:788.

5. Devriese, L.A., J. Hommez, R. Wijfels, and F. Haesebrouck. 1991. Composition of the enterococcal and streptococcal intestinal flora of poultry. J. Appl. Bacteriol. 71: $46-50$.

6. Klein, G. 2003. Taxonomy, ecology and antibiotic resistance of enterococci from food and the gastro-intestinal tract. Int. J. Food Microbiol. 88:123-131.

7. Fisher, K., and C. Phillips. 2009. The ecology, epidemiology and virulence of Enterococcus. Microbiology. 155: 1749-1757.

8. Gilmore, M.S., F. Lebreton, and S.W. van. 2013. Genomic transition of enterococci from gut commensals to leading causes of multidrug-resistant hospital infection in the antibiotic era. Curr. Opin. Microbiol. 16: $10-16$.

9. Lebreton, F., R.J.L. Willems, and M.S. Gilmore. 2014. Enterococcus diversity, origins in nature, and gut colonization. In M. S. Gilmore, D. B. Clewell, Y. Ike, and N. Shankar (eds.), Enterococci: From Commensals to Leading Causes of Drug Resistant Infection. Boston, Massachusetts Eye and Ear Infirmary.

10. Neelakanta, A., S. Sharma, V.P. Kesani, M. Salim, A. Pervaiz, N. Aftab, T. Mann, N. Tashtoush, S. Karino, S. Dhar, and K.S. Kaye. 2015. Impact of changes in the NHSN catheter-associated urinary tract infection (CAUTI) surveillance criteria on the frequency and epidemiology of CAUTI in intensive care units (ICUs). Infect. Control Hosp. Epidemiol. 36:346-349.

11. Lebreton, F., S.W. van, A.M. McGuire, P. Godfrey, A. Griggs, V. Mazumdar, J. Corander, L. Cheng, S. Saif, S. Young, Q. Zeng, J. Wortman, B. Birren, R.J. Willems, A.M. Earl, and M.S. Gilmore. 2013. Emergence of epidemic multidrug-resistant Enterococcus faecium from animal and commensal strains. MBio. 4:e00534-13.

12. Cetinkaya, Y., P. Falk, and C.G. Mayhall. 2000. Vancomycinresistant enterococci. Clin. Microbiol. Rev. 13:686-707.

13. Tenover, F.C., and L.C. McDonald. 2005. Vancomycinresistant staphylococci and enterococci: epidemiology and control. Curr. Opin. Infect. Dis. 18:300-305.
14. Zirakzadeh, A., and R. Patel. 2006. Vancomycin-resistant enterococci: colonization, infection, detection, and treatment. Mayo Clin. Proc. 81:529-536.

15. Arias, C.A., and B.E. Murray. 2012. The rise of the Enterococcus: beyond vancomycin resistance. Nat. Rev. Microbiol. 10:266-278.

16. Balli, E.P., C.A. Venetis, and S. Miyakis. 2014. Systematic review and meta-analysis of linezolid versus daptomycin for treatment of vancomycin-resistant enterococcal bacteremia. Antimicrob. Agents Chemother. 58:734-739.

17. Bourgeois-Nicolaos, N., T.T. Nguyen, G. Defrance, L. Massias, L. Alavoine, A. Lefort, V. Noel, E. Senneville, F. Doucet-Populaire, F. Mentre, A. Andremont, and X. Duval. 2014. The emergence of linezolid resistance among Enterococci in intestinal microbiota of treated patients is unrelated to individual pharmacokinetic characteristics. Antimicrob. Agents Chemother. 58:2681-2687.

18. Kristich, C.J., L.B. Rice, and C.A. Arias. 2014. Enterococcal infection-treatment and antibiotic resistance. In M. S. Gilmore, D. B. Clewell, Y. Ike, and N. Shankar, (eds.), Enterococci: From Commensals to Leading Causes of Drug Resistant Infection. Boston, Massachusetts Eye and Ear Infirmary.

19. Kelesidis, T., R. Humphries, D.Z. Uslan, and D.A. Pegues. 2011. Daptomycin nonsusceptible enterococci: an emerging challenge for clinicians. Clin. Infect. Dis. 52:228-234.

20. Niebel, M., J. Quick, A.M. Prieto, R.L. Hill, R. Pike, D. Huber, M. David, M. Hornsey, D. Wareham, B. Oppenheim, N. Woodford, S.W. van, and N. Loman. 2015. Deletions in a ribosomal protein-coding gene are associated with tigecycline resistance in Enterococcus faecium. Int. J. Antimicrob. Agents. 46:572-575.

21. Leclercq, R., E. Derlot, J. Duval, and P. Courvalin. 1988. Plasmid-mediated resistance to vancomycin and teicoplanin in Enterococcus faecium. N. Engl. J. Med. 319: $157-161$.

22. Uttley, A.H., C.H. Collins, J. Naidoo, and R.C. George. 1988. Vancomycin-resistant enterococci. Lancet. 1:57-58.

23. Willems, R.J., J. Top, S.M. van, D.A. Robinson, T.M. Coque, F. Baquero, H. Grundmann, and M.J. Bonten. 2005. Global spread of vancomycin-resistant Enterococcus faecium from distinct nosocomial genetic complex. Emerg. Infect. Dis. 11:821-828.

24. Brandl, K., G. Plitas, C.N. Mihu, C. Ubeda, T. Jia, M. Fleisher, B. Schnabl, R.P. DeMatteo, and E.G. Pamer. 2008. Vancomycin-resistant enterococci exploit antibioticinduced innate immune deficits. Nature. 455:804-807.

25. Drees, M., D.R. Snydman, C.H. Schmid, L. Barefoot, K. Hansjosten, P.M. Vue, M. Cronin, S.A. Nasraway, and Y. Golan. 2008. Prior environmental contamination increases the risk of acquisition of vancomycin-resistant enterococci. Clin. Infect. Dis. 46:678-685.

26. Byappanahalli, M.N., M.B. Nevers, A. Korajkic, Z.R. Staley, and V.J. Harwood. 2012. Enterococci in the environment. Microbiol. Mol. Biol. Rev. 76:685-706.

27. Shaghaghian, S., B. Pourabbas, A. Alborzi, M. Askarian, and J. Mardaneh. 2012. Vancomycin-Resistant Entrococci colonization in chronic hemodialysis patients and its risk factors in southern Iran (2005-2006). Iran Red. Crescent. Med. J. 14:686-691.

28. Devriese, L.A., M. Ieven, H. Goossens, P. Vandamme, B. Pot, J. Hommez, and F. Haesebrouck. 1996. Presence of vancomycin-resistant enterococci in farm and pet animals. Antimicrob. Agents Chemother. 40:2285-2287. 
29. Gholizadeh, Y., and P. Courvalin. 2000. Acquired and intrinsic glycopeptide resistance in enterococci. Int. J. Antimicrob. Agents 16 Suppl. 1:S11-S17.

30. Willems, R.J., W.P. Hanage, D.E. Bessen, and E.J. Feil. 2011. Population biology of Gram-positive pathogens: high-risk clones for dissemination of antibiotic resistance. FEMS Microbiol. Rev. 35:872-900.

31. Arthur, M., and R. Quintiliani, Jr. 2001. Regulation of VanA- and VanB-type glycopeptide resistance in enterococci. Antimicrob. Agents Chemother. 45:375-381.

32. Courvalin, P. 2006. Vancomycin resistance in grampositive cocci. Clin. Infect. Dis. 42 Suppl. 1:S25-S34.

33. Reynolds, P.E. 1998. Control of peptidoglycan synthesis in vancomycin-resistant enterococci: D,D-peptidases and D,D-carboxypeptidases. Cell Mol. Life Sci. 54:325-331.

34. Reynolds, P.E., and P. Courvalin. 2005. Vancomycin resistance in enterococci due to synthesis of precursors terminating in D-alanyl-D-serine. Antimicrob. Agents Chemother. 49:21-25.

35. Sujatha, S., and I. Praharaj. 2012. Glycopeptide resistance in gram-positive cocci: a review. Interdiscip. Perspect. Infect. Dis. 2012:10.

36. Mendez-Alvarez, S., X. Perez-Hernandez, and F. ClaverieMartin. 2000. Glycopeptide resistance in enterococci. Int. Microbiol. 3:71-80.

37. Nilsson, O. 2012. Vancomycin resistant enterococci in farm animals-occurrence and importance. Infect. Ecol. Epidemiol. 2:16959.

38. Arthur, M., and P. Courvalin. 1993. Genetics and mechanisms of glycopeptide resistance in enterococci. Antimicrob. Agents Chemother. 37:1563-1571.

39. Dahl, K.H., G.S. Simonsen, O. Olsvik, and A. Sundsfjord. 1999. Heterogeneity in the vanB gene cluster of genomically diverse clinical strains of vancomycin-resistant enterococci. Antimicrob. Agents Chemother. 43:1105-1110.

40. Dahl, K.H., T.P. Rokenes, E.W. Lundblad, and A. Sundsfjord. 2003. Nonconjugative transposition of the vanB-containing Tn5382-like element in Enterococcus faecium. Antimicrob. Agents Chemother. 47:786-789.

41. Naser, S.M., M. Vancanneyt, B. Hoste, C. Snauwaert, K. Vandemeulebroecke, and J. Swings. 2006. Reclassification of Enterococcus flavescens Pompei et al. 1992 as a later synonym of Enterococcus casseliflavus (ex Vaughan et al. 1979) Collins et al. 1984 and Enterococcus saccharominimus Vancanneyt et al. 2004 as a later synonym of Enterococcus italicus Fortina et al. 2004. Int. J. Syst. Evol. Microbiol. 56:413-416.

42. Dutta, I., and P.E. Reynolds. 2002. Biochemical and genetic characterization of the vanC-2 vancomycin resistance gene cluster of Enterococcus casseliflavus ATCC 25788. Antimicrob. Agents Chemother. 46:3125-3132.

43. Depardieu, F., M. Kolbert, H. Pruul, J. Bell, and P. Courvalin. 2004. VanD-type vancomycin-resistant Enterococcus faecium and Enterococcus faecalis. Antimicrob. Agents Chemother. 48:3892-3904.

44. Depardieu, F., P.E. Reynolds, and P. Courvalin. 2003. VanD-type vancomycin-resistant Enterococcus faecium 10/96A. Antimicrob. Agents Chemother. 47:7-18.

45. Perichon, B., P. Reynolds, and P. Courvalin. 1997. VanDtype glycopeptide-resistant Enterococcus faecium BM4339. Antimicrob. Agents Chemother. 41:2016-2018.

46. Fines, M., B. Perichon, P. Reynolds, D.F. Sahm, and P. Courvalin. 1999. VanE, a new type of acquired glyco- peptide resistance in Enterococcus faecalis BM4405. Antimicrob. Agents Chemother. 43:2161-2164.

47. McKessar, S.J., A.M. Berry, J.M. Bell, J.D. Turnidge, and J.C. Paton. 2000. Genetic characterization of vanG, a novel vancomycin resistance locus of Enterococcus faecalis. Antimicrob. Agents Chemother. 44:3224-3228.

48. Boyd, D.A., B.M. Willey, D. Fawcett, N. Gillani, and M.R. Mulvey. 2008. Molecular characterization of Enterococcus faecalis N06-0364 with low-level vancomycin resistance harboring a novel D-Ala-D-Ser gene cluster, vanL. Antimicrob. Agents Chemother. 52:2667-2672.

49. Xu, X., D. Lin, G. Yan, X. Ye, S. Wu, Y. Guo, D. Zhu, F. $\mathrm{Hu}$, Y. Zhang, F. Wang, G.A. Jacoby, and M. Wang. 2010. vanM, a new glycopeptide resistance gene cluster found in Enterococcus faecium. Antimicrob. Agents Chemother. 54:4643-4647.

50. Lebreton, F., F. Depardieu, N. Bourdon, M. Fines-Guyon, P. Berger, S. Camiade, R. Leclercq, P. Courvalin, and V. Cattoir. 2011. D-Ala-d-Ser VanN-type transferable vancomycin resistance in Enterococcus faecium. Antimicrob. Agents Chemother. 55:4606-4612.

51. Patel, R., K. Piper, F.R. Cockerill, III, J.M. Steckelberg, and A.A. Yousten. 2000. The biopesticide Paenibacillus popilliae has a vancomycin resistance gene cluster homologous to the enterococcal VanA vancomycin resistance gene cluster. Antimicrob. Agents Chemother. 44:705-709.

52. Werner, G., I. Klare, C. Fleige, and W. Witte. 2008. Increasing rates of vancomycin resistance among Enterococcus faecium isolated from German hospitals between 2004 and 2006 are due to wide clonal dissemination of vancomycin-resistant enterococci and horizontal spread of vanA clusters. Int. J. Med. Microbiol. 298:515-527.

53. Werner, G., T.M. Coque, A.M. Hammerum, R. Hope, W. Hryniewicz, A. Johnson, I. Klare, K.G. Kristinsson, R. Leclercq, C.H. Lester, M. Lillie, C. Novais, B. OlssonLiljequist, L.V. Peixe, E. Sadowy, G.S. Simonsen, J. Top, J. Vuopio-Varkila, R.J. Willems, W. Witte, and N. Woodford. 2008. Emergence and spread of vancomycin resistance among enterococci in Europe. Euro. Surveill. 13:pii: 19046.

54. Werner, G., I. Klare, and W. Witte. 1997. Arrangement of the vanA gene cluster in enterococci of different ecological origin. FEMS Microbiol. Lett. 155:55-61.

55. Mallon, D.J., J.E. Corkill, S.M. Hazel, J.S. Wilson, N.P. French, M. Bennett, and C.A. Hart. 2002. Excretion of vancomycin-resistant enterococci by wild mammals. Emerg. Infect. Dis. 8:636-638.

56. Caplin, J.L., G.W. Hanlon, and H.D. Taylor. 2008. Presence of vancomycin and ampicillin-resistant Enterococcus faecium of epidemic clonal complex-17 in wastewaters from the south coast of England. Environ. Microbiol. 10:885-892.

57. Woodford, N. 1998. Glycopeptide-resistant enterococci: a decade of experience. J. Med. Microbiol. 47:849-862.

58. Woodford, N. 2001. Epidemiology of the genetic elements responsible for acquired glycopeptide resistance in enterococci. Microb. Drug Resist. 7:229-236.

59. Shepard, B.D., and M.S. Gilmore. 2002. Antibiotic-resistant enterococci: the mechanisms and dynamics of drug introduction and resistance. Microbes. Infect. 4:215-224.

60. Klare, I., C. Konstabel, D. Badstubner, G. Werner, and W. Witte. 2003. Occurrence and spread of antibiotic resistances in Enterococcus faecium. Int. J. Food Microbiol. 88:269-290. 
61. Hegstad, K., T. Mikalsen, T.M. Coque, G. Werner, and A. Sundsfjord. 2010. Mobile genetic elements and their contribution to the emergence of antimicrobial resistant Enterococcus faecalis and Enterococcus faecium. Clin. Microbiol. Infect. 16:541-554.

62. Woodford, N., A.P. Johnson, D. Morrison, and D.C Speller. 1995. Current perspectives on glycopeptide resistance. Clin. Microbiol. Rev. 8:585-615.

63. Werner, G., A.R. Freitas, T.M. Coque, J.E. Sollid, C. Lester, A.M. Hammerum, L. Garcia-Migura, L.B. Jensen, M.V. Francia, W. Witte, R.J. Willems, and A. Sundsfjord. 2011. Host range of enterococcal vanA plasmids among Gram-positive intestinal bacteria. J. Antimicrob. Chemother. 66:273-282.

64. Launay, A., S.A. Ballard, P.D. Johnson, M.L. Grayson, and T. Lambert. 2006. Transfer of vancomycin resistance transposon Tn1549 from Clostridium symbiosum to Enterococcus spp. in the gut of gnotobiotic mice. Antimicrob. Agents Chemother. 50:1054-1062.

65. Lopez, M., J.C. Hormazabal, A. Maldonado, G. Saavedra, F. Baquero, J. Silva, C. Torres, and C.R. del. 2009. Clonal dissemination of Enterococcus faecalis ST201 and Enterococcus faecium CC17-ST64 containing Tn5382-vanB2 among 16 hospitals in Chile. Clin. Microbiol. Infect. 15: $586-588$

66. Tsvetkova, K., J.C. Marvaud, and T. Lambert. 2010. Analysis of the mobilization functions of the vancomycin resistance transposon Tn1549, a member of a new family of conjugative elements. J. Bacteriol. 192:702-713.

67. Zheng, B., H. Tomita, T. Inoue, and Y. Ike. 2009. Isolation of VanB-type Enterococcus faecalis strains from nosocomial infections: first report of the isolation and identification of the pheromone-responsive plasmids pMG2200, Encoding VanB-type vancomycin resistance and a Bac41-type bacteriocin, and pMG2201, encoding erythromycin resistance and cytolysin (Hly/Bac). Antimicrob. Agents Chemother. 53:735-747.

68. Werner, G., I. Klare, C. Fleige, U. Geringer, W. Witte, H.M. Just, and R. Ziegler. 2012. Vancomycin-resistant vanB-type Enterococcus faecium isolates expressing varying levels of vancomycin resistance and being highly prevalent among neonatal patients in a single ICU. Antimicrob. Resist. Infect. Control. 1:21.

69. Casadewall, B., and P. Courvalin. 1999. Characterization of the vanD glycopeptide resistance gene cluster from Enterococcus faecium BM4339. J. Bacteriol. 181:36443648.

70. Dalla Costa, L.M., P.E. Reynolds, H.A. Souza, D.C. Souza, M.F. Palepou, and N. Woodford. 2000. Characterization of a divergent vanD-type resistance element from the first glycopeptide-resistant strain of Enterococcus faecium isolated in Brazil. Antimicrob. Agents Chemother. 44:3444-3446.

71. Casadewall, B., P.E. Reynolds, and P. Courvalin. 2001. Regulation of expression of the vanD glycopeptide resistance gene cluster from Enterococcus faecium BM4339. J. Bacteriol. 183:3436-3446.

72. Boyd, D.A., P. Kibsey, D. Roscoe, and M.R. Mulvey. 2004. Enterococcus faecium N03-0072 carries a new VanD-type vancomycin resistance determinant: characterization of the VanD5 operon. J. Antimicrob. Chemother. 54:680-683.

73. Depardieu, F., M.L. Foucault, J. Bell, A. Dubouix, M. Guibert, J.P. Lavigne, M. Levast, and P. Courvalin. 2009.
New combinations of mutations in VanD-Type vancomycin-resistant Enterococcus faecium, Enterococcus faecalis, and Enterococcus avium strains. Antimicrob. Agents Chemother. 53:1952-1963.

74. Boyd, D.A., M.A. Miller, and M.R. Mulvey. 2006. Enterococcus gallinarum N04-0414 harbors a VanD-type vancomycin resistance operon and does not contain a Dalanine:D-alanine 2 (dd12) gene. Antimicrob. Agents Chemother. 50:1067-1070.

75. Boyd, D.A., T. Cabral, C.P. Van, J. Wylie, and M.R. Mulvey. 2002. Molecular characterization of the vanE gene cluster in vancomycin-resistant Enterococcus faecalis N00-410 isolated in Canada. Antimicrob. Agents Chemother. 46:1977-1979.

76. Abadia-Patino, L., K. Christiansen, J. Bell, P. Courvalin, and B. Perichon. 2004. VanE-type vancomycin-resistant Enterococcus faecalis clinical isolates from Australia. Antimicrob. Agents Chemother. 48:4882-4885.

77. Depardieu, F., M.G. Bonora, P.E. Reynolds, and P. Courvalin. 2003. The vanG glycopeptide resistance operon from Enterococcus faecalis revisited. Mol. Microbiol. 50:931-948.

78. Boyd, D.A., T. Du, R. Hizon, B. Kaplen, T. Murphy, S. Tyler, S. Brown, F. Jamieson, K. Weiss, and M.R. Mulvey. 2006. VanG-type vancomycin-resistant Enterococcus faecalis strains isolated in Canada. Antimicrob. Agents Chemother. 50:2217-2221.

79. Szakacs, T.A., L. Kalan, M.J. McConnell, A. Eshaghi, D. Shahinas, A. McGeer, G.D. Wright, D.E. Low, and S.N. Patel. 2014. Outbreak of vancomycin-susceptible Enterococcus faecium containing the wild-type vanA gene. J. Clin. Microbiol. 52:1682-1686.

80. Choi, S.H., S.O. Lee, T.H. Kim, J.W. Chung, E.J. Choo, Y.G. Kwak, M.N. Kim, Y.S. Kim, J.H. Woo, J. Ryu, and N.J. Kim. 2004. Clinical features and outcomes of bacteremia caused by Enterococcus casseliflavus and Enterococcus gallinarum: analysis of 56 cases. Clin. Infect. Dis. 38:53-61.

81. Togneri, A., H. Lopardo, and A. Corso. 2003. [Bacteremia caused by Enterococcus gallinarum with a high level of glycopeptide resistance: 1st documented cases in Argentina]. Rev. Argent Microbiol. 35:96-99.

82. Chan, Y.Y., M.H. Abd Nasir, M.A. Yahaya, N.M. Salleh, A.D. Md Dan, A.M. Musa, and M. Ravichandran. 2008. Low prevalence of vancomycin- and bifunctional aminoglycoside-resistant enterococci isolated from poultry farms in Malaysia. Int. J. Food Microbiol. 122:221-226.

83. Contreras, G.A., C.A. DiazGranados, L. Cortes, J. Reyes, S. Vanegas, D. Panesso, S. Rincon, L. Diaz, G. Prada, B.E. Murray, and C.A. Arias. 2008. Nosocomial outbreak of Enteroccocus gallinarum: untaming of rare species of enterococci. J. Hosp. Infect. 70:346-352.

84. Koganemaru, H., and S. Hitomi. 2008. Bacteremia caused by VanC-type enterococci in a university hospital in Japan: a 6-year survey. J. Infect. Chemother. 14:413-417.

85. Tan, C.K., C.C. Lai, J.Y. Wang, S.H. Lin, C.H. Liao, Y.T. Huang, C.Y. Wang, H.I. Lin, and P.R. Hsueh. 2010. Bacteremia caused by non-faecalis and non-faecium enterococcus species at a Medical center in Taiwan, 2000 to 2008. J. Infect. 61:34-43.

86. Gikas, A., A. Christidou, E. Scoulica, P. Nikolaidis, A. Skoutelis, S. Levidiotou, S. Kartali, E. Maltezos, S. Metalidis, J. Kioumis, G. Haliotis, S. Dima, M. Roumbelaki, N. Papageorgiou, E.I. Kritsotakis, and Y. Tselentis. 2005. 
Epidemiology and molecular analysis of intestinal colonization by vancomycin-resistant enterococci in greek hospitals. J. Clin. Microbiol. 43:5796-5799.

87. Tschudin, S.S., R. Frei, M. Dangel, A. Gratwohl, M. Bonten, and A.F. Widmer. 2010. Not all patients with vancomycin-resistant enterococci need to be isolated. Clin. Infect. Dis. 51:678-683.

88. Dziri, R., C. Lozano, S.L. Ben, R. Bellaaj, A. Boudabous, S.K. Ben, C. Torres, and N. Klibi. 2016. Multidrugresistant enterococci in the hospital environment: detection of novel vancomycin-resistant $\mathrm{E}$. faecium clone ST910. J. Infect. Dev. Ctries. 10:799-806.

89. Panesso, D., L. Abadia-Patino, N. Vanegas, P.E. Reynolds, P. Courvalin, and C.A. Arias. 2005. Transcriptional analysis of the vanC cluster from Enterococcus gallinarum strains with constitutive and inducible vancomycin resistance. Antimicrob. Agents Chemother. 49:1060-1066.

90. Foglia, G., G.M. Del, C. Vignaroli, P. Bagnarelli, P.E. Varaldo, A. Pantosti, and F. Biavasco. 2003. Molecular analysis of Tn1546-like elements mediating high-level vancomycin resistance in Enterococcus gallinarum. J. Antimicrob. Chemother. 52:772-775.

91. Haenni, M., E. Saras, P. Chatre, D. Meunier, S. Martin, G. Lepage, M.F. Menard, P. Lebreton, T. Rambaud, and J.Y. Madec. 2009. vanA in Enterococcus faecium, Enterococcus faecalis, and Enterococcus casseliflavus detected in French cattle. Foodborne. Pathog. Dis. 6:1107-1111.

92. Neves, F.P., R.L. Ribeiro, R.S. Duarte, L.M. Teixeira, and V.L. Merquior. 2009. Emergence of the vanA genotype among Enterococcus gallinarum isolates colonising the intestinal tract of patients in a university hospital in Rio de Janeiro, Brazil. Int. J. Antimicrob. Agents. 33:211-215.

93. Camargo, I.L., A.L. Barth, K. Pilger, B.G. Seligman, A.R. Machado, and A.L. Darini. 2004. Enterococcus gallinarum carrying the vanA gene cluster: first report in Brazil. Braz. J. Med. Biol. Res. 37:1669-1671.

94. Mammina, C., A.M. Di Noto, A. Costa, and A. Nastasi. 2005. VanB-VanC1 Enterococcus gallinarum, Italy. Emerg. Infect. Dis. 11:1491-1492.

95. Dutka-Malen, S., B. Blaimont, G. Wauters, and P. Courvalin. 1994. Emergence of high-level resistance to glycopeptides in Enterococcus gallinarum and Enterococcus casseliflavus. Antimicrob. Agents Chemother. 38:1675-1677.

96. Merquior, V.L., F.P. Goncalves Neves, R.L. Ribeiro, R.S. Duarte, M.E. de Andrade, and L.M. Teixeira. 2008. Bacteraemia associated with a vancomycin-resistant Enterococcus gallinarum strain harbouring both the vanA and vanC1 genes. J. Med. Microbiol. 57:244-245.

97. Yasliani, S., M.A. Mohabati, D.R. Hosseini, M. Satari, and O. Teymornejad. 2009. Linezolid vancomycin resistant Enterococcus isolated from clinical samples in Tehran hospitals. Indian J. Med. Sci. 63:297-302.

98. Praharaj, I., S. Sujatha, and S.C. Parija. 2013. Phenotypic $\&$ genotypic characterization of vancomycin resistant Enterococcus isolates from clinical specimens. Indian $\mathbf{J}$. Med. Res. 138:549-556.

99. Corso, A., D. Faccone, P. Gagetti, A. Togneri, H. Lopardo, R. Melano, V. Rodriguez, M. Rodriguez, and M. Galas. 2005. First report of VanA Enterococcus gallinarum dissemination within an intensive care unit in Argentina. Int. J. Antimicrob. Agents. 25:51-56.

100. Liassine, N., R. Frei, I. Jan, and R. Auckenthaler. 1998. Characterization of glycopeptide-resistant enterococci from a Swiss hospital. J. Clin. Microbiol. 36:1853-1858.
101. Tacconelli, E., and M.A. Cataldo. 2008. Vancomycinresistant enterococci (VRE): transmission and control. Int. J. Antimicrob. Agents. 31:99-106.

102. Emaneini, M., F. Hosseinkhani, F. Jabalameli, M.J. Nasiri, M. Dadashi, R. Pouriran, and R. Beigverdi. 2016. Prevalence of vancomycin-resistant Enterococcus in Iran: a systematic review and meta-analysis. Eur. J. Clin. Microbiol. Infect. Dis. 35:1387-1392.

103. Rice, L.B. 2001. Emergence of vancomycin-resistant enterococci. Emerg. Infect. Dis. 7:183-187.

104. Jahansepas, A., M. Aghazadeh, R.M. Ahangarzadeh, A. Hasani, Y. Sharifi, T. Aghazadeh, and J. Mardaneh. 2017. Occurrence of Enterococcus faecalis and Enterococcus faecium in various clinical infections: detection of their drug resistance and virulence determinants. microb. drug resist. [Epub ahead of print]; DOI: 10.1089/mdr.2017 .0049 .

105. Del, G.M., A. Caprioli, P. Chinzari, M.C. Fontana, G. Pezzotti, A. Manfrin, E.D. Giannatale, E. Goffredo, and A. Pantosti. 2000. Detection and characterization of vancomycin-resistant enterococci in farm animals and raw meat products in Italy. Microb. Drug Resist. 6:313-318.

106. Johnson, P.D., S.A. Ballard, E.A. Grabsch, T.P. Stinear, T. Seemann, H.L. Young, M.L. Grayson, and B.P. Howden. 2010. A sustained hospital outbreak of vancomycinresistant Enterococcus faecium bacteremia due to emergence of vanB E. faecium sequence type 203. J. Infect. Dis. 202:1278-1286.

107. Soderblom, T., O. Aspevall, M. Erntell, G. Hedin, D. Heimer, I. Hokeberg, K. Kidd-Ljunggren, A. Melhus, B. Olsson-Liljequist, I. Sjogren, J. Smedjegard, J. Struwe, S. Sylvan, K. Tegmark-Wisell, and M. Thore. 2010. Alarming spread of vancomycin resistant enterococci in Sweden since 2007. Euro. Surveill. 15: pii: 19620.

108. Bender, J.K., A. Kalmbach, C. Fleige, I. Klare, S. Fuchs, and G. Werner. 2016. Population structure and acquisition of the vanB resistance determinant in German clinical isolates of Enterococcus faecium ST192. Sci. Rep. 6: 21847.

109. Padiglione, A.A., E.A. Grabsch, D. Olden, M. Hellard, M.I. Sinclair, C.K. Fairley, and M.L. Grayson. 2000. Fecal colonization with vancomycin-resistant enterococci in Australia. Emerg. Infect. Dis. 6:534-536.

110. Stinear, T.P., D.C. Olden, P.D. Johnson, J.K. Davies, and M.L. Grayson. 2001. Enterococcal vanB resistance locus in anaerobic bacteria in human faeces. Lancet. 357:855-856.

111. Schooneveldt, J.M., R.K. Marriott, and G.R. Nimmo. 2000. Detection of a vanB determinant in Enterococcus gallinarum in Australia. J. Clin. Microbiol. 38:3902.

112. de Garnica, M.L., S. Valdezate, C. Gonzalo, and J.A. Saez-Nieto. 2013. Presence of the vanC1 gene in a vancomycin-resistant Enterococcus faecalis strain isolated from ewe bulk tank milk. J. Med. Microbiol. 62:494-495.

113. Moura, T.M., A.P. Cassenego, F.S. Campos, A.M. Ribeiro, A.C. Franco, P.A. d'Azevedo, J. Frazzon, and A.P. Frazzon. 2013. Detection of vanC1 gene transcription in vancomycin-susceptible Enterococcus faecalis. Mem. Inst. Oswaldo Cruz. 108:453-456.

114. Sun, M., Y. Wang, Z. Chen, X. Zhu, L. Tian, and Z. Sun. 2014. The first report of the vanC(1) gene in Enterococcus faecium isolated from a human clinical specimen. Mem. Inst. Oswaldo Cruz. 109:712-715.

115. Abele-Horn, M., U. Vogel, I. Klare, C. Konstabel, R. Trabold, R. Kurihara, W. Witte, W. Kreth, P.G. Schlegel, 
and H. Claus. 2006. Molecular epidemiology of hospitalacquired vancomycin-resistant enterococci. J. Clin. Microbiol. 44:4009-4013.

116. Top, J., R. Willems, and M. Bonten. 2008. Emergence of CC17 Enterococcus faecium: from commensal to hospitaladapted pathogen. FEMS Immunol. Med. Microbiol. 52: 297-308.

117. Palmer, K.L., P. Godfrey, A. Griggs, V.N. Kos, J. Zucker, C. Desjardins, G. Cerqueira, D. Gevers, S. Walker, J. Wortman, M. Feldgarden, B. Haas, B. Birren, and M.S. Gilmore. 2012. Comparative genomics of enterococci: variation in Enterococcus faecalis, clade structure in $E$. faecium, and defining characteristics of E. gallinarum and E. casseliflavus. MBio. 3:e0318-11.

118. Damani, A., D. Klapsa, M. Panopoulou, I. Spiliopoulou, K. Pantelidi, E. Malli, F. Kolonitsiou, S. Grapsa, E. Alepopoulou, F. Frantzidou, E. Vlahaki, C. Koutsia-Carouzou, H. Malamou-Lada, L. Zerva, S. Kartali-Ktenidou, E.D. Anastassiou, A.N. Maniatis, and E. Petinaki. 2010. A newly described vancomycin-resistant ST412 Enterococcus faecium predominant in Greek hospitals. Eur. J. Clin. Microbiol. Infect. Dis. 29:329-331.

119. Homan, W.L., D. Tribe, S. Poznanski, M. Li, G. Hogg, E. Spalburg, J.D. Van Embden, and R.J. Willems. 2002. Multilocus sequence typing scheme for Enterococcus faecium. J. Clin. Microbiol. 40:1963-1971.

120. Buultjens, A.H., M.M. Lam, S. Ballard, I.R. Monk, A.A. Mahony, E.A. Grabsch, M.L. Grayson, S. Pang, G.W. Coombs, J.O. Robinson, T. Seemann, P.D. Johnson, B.P. Howden, and T.P. Stinear. 2017. Evolutionary origins of the emergent ST796 clone of vancomycin resistant Enterococcus faecium. PeerJ. 5:e2916.

121. Hullahalli, K., M. Rodrigues, B.D. Schmidt, X. Li, P. Bhardwaj, and K.L. Palmer. 2015. Comparative analysis of the orphan CRISPR2 locus in 242 Enterococcus faecalis strains. PLoS One. 10:e0138890.

122. Mikalsen, T., T. Pedersen, R. Willems, T.M. Coque, G. Werner, E. Sadowy, S.W. van, L.B. Jensen, A. Sundsfjord, and K. Hegstad. 2015. Investigating the mobilome in clinically important lineages of Enterococcus faecium and Enterococcus faecalis. BMC Genomics. 16:282.

123. Tedim, A.P., V.F. Lanza, M. Manrique, E. Pareja, P. RuizGarbajosa, R. Canton, F. Baquero, T.M. Coque, and R. Tobes. 2017. Complete genome sequences of isolates of Enterococcus faecium sequence type 117, a globally disseminated multidrug-resistant clone. Genome Announc. 5. 13:e01553-16.

124. Elhani, D., N. Klibi, R. Dziri, H.M. Ben, M.S. Asli, S.L. Ben, A. Mahjoub, S.K. Ben, B. Jemli, R. Bellaj, F. Barguellil, and C. Torres. 2014. vanA-containing E. faecium isolates of clonal complex $\mathrm{CC} 17$ in clinical and environmental samples in a Tunisian hospital. Diagn. Microbiol. Infect. Dis. 79:60-63.

125. Merlo, T.P., A.N. Dabul, and I.L. Camargo. 2015. Different VanA Elements in E. faecalis and in E. faecium suggest at least two origins of Tn1546 among VRE in a Brazilian Hospital. Microb. Drug Resist. 21:320-328.

126. Feil, E.J., B.C. Li, D.M. Aanensen, W.P. Hanage, and B.G. Spratt. 2004. eBURST: inferring patterns of evolutionary descent among clusters of related bacterial genotypes from multilocus sequence typing data. J. Bacteriol. 186:1518-1530.

127. Corander, J., P. Marttinen, J. Siren, and J. Tang. 2008. Enhanced Bayesian modelling in BAPS software for learning genetic structures of populations. BMC Bioinform. 9:539.

128. Stampone, L., G.M. Del, D. Boccia, and A. Pantosti. 2005. Clonal spread of a vancomycin-resistant Enterococcus faecium strain among bloodstream-infecting isolates in Italy. J. Clin. Microbiol. 43:1575-1580.

129. Werner, G., C. Fleige, U. Geringer, S.W. van, I. Klare, and W. Witte. 2011. IS element IS16 as a molecular screening tool to identify hospital-associated strains of Enterococcus faecium. BMC Infect. Dis. 11:80.

130. Ruiz-Garbajosa, P., M.J. Bonten, D.A. Robinson, J. Top, S.R. Nallapareddy, C. Torres, T.M. Coque, R. Canton, F. Baquero, B.E. Murray, C.R. del, and R.J. Willems. 2006. Multilocus sequence typing scheme for Enterococcus faecalis reveals hospital-adapted genetic complexes in a background of high rates of recombination. J. Clin. Microbiol. 44:2220-2228.

131. Freitas, A.R., C. Novais, P. Ruiz-Garbajosa, T.M. Coque, and L. Peixe. 2009. Clonal expansion within clonal complex 2 and spread of vancomycin-resistant plasmids among different genetic lineages of Enterococcus faecalis from Portugal. J. Antimicrob. Chemother. 63:1104-1111.

132. Lopez, M., Y. Saenz, M.J. Alvarez-Martinez, F. Marco, B. Robredo, B. Rojo-Bezares, F. Ruiz-Larrea, M. Zarazaga, and C. Torres. 2010. Tn1546 structures and multilocus sequence typing of vanA-containing enterococci of animal, human and food origin. J. Antimicrob. Chemother. 65:1570-1575.

133. Raven, K.E., T. Gouliouris, H. Brodrick, F. Coll, N.M. Brown, R. Reynolds, S. Reuter, M.E. Torok, J. Parkhill, and S.J. Peacock. 2017. Complex routes of nosocomial vancomycin-resistant Enterococcus faecium transmission revealed by genome sequencing. Clin. Infect. Dis. 64:886-893.

134. Aarestrup, F.M. 2000. Occurrence, selection and spread of resistance to antimicrobial agents used for growth promotion for food animals in Denmark. APMIS Suppl. 101:1-48.

135. Aarestrup, F.M., H. Kruse, E. Tast, A.M. Hammerum, and L.B. Jensen. 2000. Associations between the use of antimicrobial agents for growth promotion and the occurrence of resistance among Enterococcus faecium from broilers and pigs in Denmark, Finland, and Norway. Microb. Drug Resist. 6:63-70.

136. Heuer, O.E., K. Pedersen, J.S., Andersen, and M. Madsen. 2002. Vancomycin-resistant enterococci (VRE) in broiler flocks 5 years after the avoparcin ban. Microb. Drug Resist. 8:133-138.

137. Bustamante, W., A. Alpizar, S. Hernandez, A. Pacheco, N. Vargas, M.L. Herrera, A. Vargas, M. Caballero, and F. Garcia. 2003. Predominance of vanA genotype among vancomycin-resistant Enterococcus isolates from poultry and swine in Costa Rica. Appl. Environ. Microbiol. 69: 7414-7419.

138. Smith, D.L., J.A. Johnson, A.D. Harris, J.P. Furuno, E.N. Perencevich, and J.G. Morris, Jr. 2003. Assessing risks for a pre-emergent pathogen: virginiamycin use and the emergence of streptogramin resistance in Enterococcus faecium. Lancet Infect. Dis. 3:241-249.

139. Hammerum, A.M. 2012. Enterococci of animal origin and their significance for public health. Clin. Microbiol. Infect. 18:619-625.

140. Klare, I., H. Heier, H. Claus, G. Bohme, S. Marin, G. Seltmann, R. Hakenbeck, V. Antanassova, and W. Witte. 1995. Enterococcus faecium strains with vanA-mediated 
high-level glycopeptide resistance isolated from animal foodstuffs and fecal samples of humans in the community. Microb. Drug Resist. 1:265-272.

141. Klare, I., H. Heier, H. Claus, R. Reissbrodt, and W. Witte. 1995. vanA-mediated high-level glycopeptide resistance in Enterococcus faecium from animal husbandry. FEMS Microbiol. Lett. 125:165-171.

142. Simonsen, G.S., H. Haaheim, K.H. Dahl, H. Kruse, A. Lovseth, O. Olsvik, and A. Sundsfjord. 1998. Transmission of VanA-type vancomycin-resistant enterococci and vanA resistance elements between chicken and humans at avoparcin-exposed farms. Microb. Drug Resist. 4:313-318.

143. Ramos, S., G. Igrejas, J. Rodrigues, J.L. Capelo-Martinez, and P. Poeta. 2012. Genetic characterisation of antibiotic resistance and virulence factors in vanA-containing enterococci from cattle, sheep and pigs subsequent to the discontinuation of the use of avoparcin. Vet. J. 193:301-303.

144. Novais, C., T.M. Coque, M.J. Costa, J.C. Sousa, F. Baquero, and L.V. Peixe. 2005. High occurrence and persistence of antibiotic-resistant enterococci in poultry food samples in Portugal. J. Antimicrob. Chemother. $56: 1139-1143$.

145. Centre for Disease Control and Prevention (CDC). 1993. Nosocomial enterococci resistant to vancomycin-United States, 1989-1993. MMWR Morbid. Mortal. Wkly. Rep. 42:597-599.

146. Leclercq, R., and P. Courvalin. 1997. Resistance to glycopeptides in enterococci. Clin. Infect. Dis. 24:545-554.

147. Bell, J., J. Turnidge, G. Coombs, and F. O'Brien. 1998. Emergence and epidemiology of vancomycin-resistant enterococci in Australia. Commun. Dis. Intell. 22:249-252.

148. Klare, I., D. Badstubner, C. Konstabel, G. Bohme, H. Claus, and W. Witte. 1999. Decreased incidence of VanAtype vancomycin-resistant enterococci isolated from poultry meat and from fecal samples of humans in the community after discontinuation of avoparcin usage in animal husbandry. Microb. Drug Resist. 5:45-52.

149. European Antimicrobial resistance surveillance system (EARSS). 2002 annual report. Available at http://ecdc .europa.eu/en/activities/surveillance/ears-net/documentsx/ pages/documents.aspx

150. Casewell, M., C. Friis, E. Marco, P. McMullin, and I. Phillips. 2003. The European ban on growth-promoting antibiotics and emerging consequences for human and animal health. J. Antimicrob. Chemother. 52:159-161.

151. Brown, D.F., R. Hope, D.M. Livermore, G. Brick, K. Broughton, R.C. George, and R. Reynolds. 2008. Non-susceptibility trends among enterococci and nonpneumococcal streptococci from bacteraemias in the UK and Ireland, 2001-06. J. Antimicrob. Chemother. 62 Suppl. 2:ii75-ii85.

152. Sagel, U., B. Schulte, P. Heeg, and S. Borgmann. 2008. Vancomycin-resistant enterococci outbreak, Germany, and calculation of outbreak start. Emerg. Infect. Dis. 14:317-319.

153. Theilacker, C., D. Jonas, J. Huebner, H. Bertz, and W.V. Kern. 2009. Outcomes of invasive infection due to vancomycin-resistant Enterococcus faecium during a recent outbreak. Infection. 37:540-543.

154. Henard, S., A. Lozniewski, N. Aissa, N. Jouzeau, and C. Rabaud. 2011. Evaluation of the duration of vanA vancomycin-resistant Enterococcus faecium carriage and clearance during a large-scale outbreak in a region of eastern France. Am. J. Infect. Control. 39:169-171.
155. Bager, F., M. Madsen, J. Christensen, and F.M. Aarestrup. 1997. Avoparcin used as a growth promoter is associated with the occurrence of vancomycin-resistant Enterococcus faecium on Danish poultry and pig farms. Prev. Vet. Med. 31:95-112.

156. Bates, J. 1997. Epidemiology of vancomycin-resistant enterococci in the community and the relevance of farm animals to human infection. J. Hosp. Infect. 37:89-101.

157. Aarestrup, F.M., A.M. Seyfarth, H.D. Emborg, K. Pedersen, R.S. Hendriksen, and F. Bager. 2001. Effect of abolishment of the use of antimicrobial agents for growth promotion on occurrence of antimicrobial resistance in fecal enterococci from food animals in Denmark. Antimicrob. Agents Chemother. 45:2054-2059.

158. Kruse, H., B.K. Johansen, L.M. Rorvik, and G. Schaller. 1999. The use of avoparcin as a growth promoter and the occurrence of vancomycin-resistant Enterococcus species in Norwegian poultry and swine production. Microb. Drug Resist. 5:135-139.

159. Borgen, K., G.S. Simonsen, A. Sundsfjord, Y. Wasteson, O. Olsvik, and H. Kruse. 2000. Continuing high prevalence of VanA-type vancomycin-resistant enterococci on Norwegian poultry farms three years after avoparcin was banned. J. Appl. Microbiol. 89:478-485.

160. Borgen, K., M. Sorum, Y. Wasteson, and H. Kruse. 2001. VanA-type vancomycin-resistant enterococci (VRE) remain prevalent in poultry carcasses 3 years after avoparcin was banned. Int. J. Food Microbiol. 64:89-94.

161. Bortolaia, V., M. Mander, L.B. Jensen, J.E. Olsen, and L. Guardabassi. 2015. Persistence of vancomycin resistance in multiple clones of Enterococcus faecium isolated from Danish broilers 15 years after the ban of avoparcin. Antimicrob. Agents Chemother. 59:2926-2929.

162. Lauderdale, T.L., Y.R. Shiau, H.Y. Wang, J.F. Lai, I.W. Huang, P.C. Chen, H.Y. Chen, S.S. Lai, Y.F. Liu, and M. Ho. 2007. Effect of banning vancomycin analogue avoparcin on vancomycin-resistant enterococci in chicken farms in Taiwan. Environ. Microbiol. 9:819-823.

163. van, B.A., N. van den Braak, R. Thomassen, H. Verbrugh, and H. Endtz. 1996. Vancomycin-resistant enterococci in cats and dogs. Lancet. 348:1038-1039.

164. Wagenvoort, J.H., D.M. Burgers, T.H. Wagenvoort, and E. Burgers. 2003. Absence of vancomycin-resistant enterococci (VRE) in companion dogs in the conurbation of Parkstad Limburg, The Netherlands. J. Antimicrob. Chemother. 52:532.

165. Rice, E.W., L.A. Boczek, C.H. Johnson, and J.W. Messer. 2003. Detection of intrinsic vancomycin resistant enterococci in animal and human feces. Diagn. Microbiol. Infect. Dis. 46:155-158.

166. Damborg, P., A.H. Sorensen, and L. Guardabassi. 2008. Monitoring of antimicrobial resistance in healthy dogs: first report of canine ampicillin-resistant Enterococcus faecium clonal complex 17. Vet. Microbiol. 132:190-196.

167. Ossiprandi, M.C., E. Bottarelli, F. Cattabiani, and E. Bianchi. 2008. Susceptibility to vancomycin and other antibiotics of 165 Enterococcus strains isolated from dogs in Italy. Comp. Immunol. Microbiol. Infect. Dis. 31:1-9.

168. Simjee, S., D.G. White, P.F. McDermott, D.D. Wagner, M.J. Zervos, S.M. Donabedian, L.L. English, J.R. Hayes, and R.D. Walker. 2002. Characterization of Tn1546 in vancomycin-resistant Enterococcus faecium isolated from canine urinary tract infections: evidence of gene exchange 
between human and animal enterococci. J. Clin. Microbiol. 40:4659-4665.

169. Herrero, I.A., J.F. Fernandez-Garayzabal, M.A. Moreno, and L. Dominguez. 2004. Dogs should be included in surveillance programs for vancomycin-resistant enterococci. J. Clin. Microbiol. 42:1384-1385.

170. Manson, J.M., S. Keis, J.M. Smith, and G.M. Cook. 2003. Characterization of a vancomycin-resistant Enterococcus faecalis (VREF) isolate from a dog with mastitis: further evidence of a clonal lineage of VREF in New Zealand. J. Clin. Microbiol. 41:3331-3333.

171. de, N.S., C. Sabia, P. Messi, E. Guerrieri, G. Manicardi, and M. Bondi. 2007. VanA-type vancomycin-resistant enterococci in equine and swine rectal swabs and in human clinical samples. Curr. Microbiol. 55:240-246.

172. Chadwick, P.R., N. Woodford, E.B. Kaczmarski, S. Gray, R.A. Barrell, and B.A. Oppenheim. 1996. Glycopeptideresistant enterococci isolated from uncooked meat. J. Antimicrob. Chemother. 38:908-909.

173. Stobberingh, E., A. van den Bogaard, N. London, C. Driessen, J. Top, and R. Willems. 1999. Enterococci with glycopeptide resistance in turkeys, turkey farmers, turkey slaughterers, and (sub)urban residents in the south of The Netherlands: evidence for transmission of vancomycin resistance from animals to humans? Antimicrob. Agents Chemother. 43:2215-2221.

174. Bates, J., Z. Jordens, and J.B. Selkon. 1993. Evidence for an animal origin of vancomycin-resistant enterococci. Lancet. 342:490-491.

175. Bates, J., J.Z. Jordens, and D.T. Griffiths. 1994. Farm animals as a putative reservoir for vancomycin-resistant enterococcal infection in man. J. Antimicrob. Chemother. 34:507-514.

176. Goossens, H. 1998. Spread of vancomycin-resistant enterococci: differences between the United States and Europe. Infect. Control Hosp. Epidemiol. 19:546-551.

177. Berchieri, A. 1999. Intestinal colonization of a human subject by vancomycin-resistant Enterococcus faecium. Clin. Microbiol. Infect. 5:97-100.

178. Sorensen, T.L., M. Blom, D.L. Monnet, N. FrimodtMoller, R.L. Poulsen, and F. Espersen. 2001. Transient intestinal carriage after ingestion of antibiotic-resistant Enterococcus faecium from chicken and pork. N. Engl. J. Med. 345:1161-1166.

179. Hammerum, A.M., C.H. Lester, J. Neimann, L.J. Porsbo, K.E. Olsen, L.B. Jensen, H.D. Emborg, H.C. Wegener, and N. Frimodt-Moller. 2004. A vancomycin-resistant Enterococcus faecium isolate from a Danish healthy volunteer, detected 7 years after the ban of avoparcin, is possibly related to pig isolates. J. Antimicrob. Chemother. 53:547-549.

180. van den Bogaard, A.E., L.B. Jensen, and E.E. Stobberingh. 1997. Vancomycin-resistant enterococci in turkeys and farmers. N. Engl. J. Med. 337:1558-1559.

181. Willems, R.J., J. Top, B.N. van Den, B.A. van, H. Endtz, D. Mevius, E. Stobberingh, B.A. van Den, and J.D. van Embden. 2000. Host specificity of vancomycin-resistant Enterococcus faecium. J. Infect. Dis. 182:816-823.

182. Top, J., L.M. Schouls, M.J. Bonten, and R.J. Willems. 2004. Multiple-locus variable-number tandem repeat analysis, a novel typing scheme to study the genetic relatedness and epidemiology of Enterococcus faecium isolates. J. Clin. Microbiol. 42:4503-4511.

183. Ghosh, A., S.E. Dowd, and L. Zurek. 2011. Dogs leaving the ICU carry a very large multi-drug resistant entero- coccal population with capacity for biofilm formation and horizontal gene transfer. PLoS One. 6:e22451.

184. Freitas, A.R., T.M. Coque, C. Novais, A.M. Hammerum, C.H. Lester, M.J. Zervos, S. Donabedian, L.B. Jensen, M.V. Francia, F. Baquero, and L. Peixe. 2011. Human and swine hosts share vancomycin-resistant Enterococcus faecium CC17 and CC5 and Enterococcus faecalis CC2 clonal clusters harboring Tn1546 on indistinguishable plasmids. J. Clin. Microbiol. 49:925-931.

185. Lopez, M., Y. Saenz, B. Rojo-Bezares, S. Martinez, C.R. del, F. Ruiz-Larrea, M. Zarazaga, and C. Torres. 2009. Detection of vanA and vanB2-containing enterococci from food samples in Spain, including Enterococcus faecium strains of CC17 and the new singleton ST425. Int. J. Food Microbiol. 133:172-178.

186. Solheim, M., A. Aakra, L.G. Snipen, D.A. Brede, and I.F. Nes. 2009. Comparative genomics of Enterococcus faecalis from healthy Norwegian infants. BMC Genomics. 10:194.

187. Kawalec, M., Z. Pietras, E. Danilowicz, A. Jakubczak, M. Gniadkowski, W. Hryniewicz, and R.J. Willems. 2007. Clonal structure of Enterococcus faecalis isolated from Polish hospitals: characterization of epidemic clones. J. Clin. Microbiol. 45:147-153.

188. Larsen, J., H.C. Schonheyder, C.H. Lester, S.S. Olsen, L.J. Porsbo, L. Garcia-Migura, L.B. Jensen, M. Bisgaard, and A.M. Hammerum. 2010. Porcine-origin gentamicin-resistant Enterococcus faecalis in humans, Denmark. Emerg. Infect. Dis. 16:682-684.

189. Agerso, Y., C.H. Lester, L.J. Porsbo, I. Orsted, H.D. Emborg, K.E. Olsen, L.B. Jensen, O.E. Heuer, N. Frimodt-Moller, F.M. Aarestrup, and A.M. Hammerum. 2008. Vancomycin-resistant Enterococcus faecalis isolates from a Danish patient and two healthy human volunteers are possibly related to isolates from imported turkey meat. J. Antimicrob. Chemother. 62:844-845.

190. Larsen, J., H.C. Schonheyder, K.V. Singh, C.H. Lester, S.S. Olsen, L.J. Porsbo, L. Garcia-Migura, L.B. Jensen, M. Bisgaard, B.E. Murray, and A.M. Hammerum. 2011. Porcine and human community reservoirs of Enterococcus faecalis, Denmark. Emerg. Infect. Dis. 17:23952397.

191. Novais, C., A.R. Freitas, J.C. Sousa, F. Baquero, T.M. Coque, and L.V. Peixe. 2008. Diversity of Tn1546 and its role in the dissemination of vancomycin-resistant enterococci in Portugal. Antimicrob. Agents Chemother. 52: 1001-1008.

192. Willems, R.J., J. Top, N. van den Braak, B.A. van, D.J. Mevius, G. Hendriks, M. van Santen-Verheuvel, and J.D. van Embden. 1999. Molecular diversity and evolutionary relationships of Tn1546-like elements in enterococci from humans and animals. Antimicrob. Agents Chemother. 43:483-491.

193. Biavasco, F., G. Foglia, C. Paoletti, G. Zandri, G. Magi, E. Guaglianone, A. Sundsfjord, C. Pruzzo, G. Donelli, and B. Facinelli. 2007. VanA-type enterococci from humans, animals, and food: species distribution, population structure, Tn1546 typing and location, and virulence determinants. Appl. Environ. Microbiol. 73: 3307-3319.

194. Jensen, L.B., P. Ahrens, L. Dons, R.N. Jones, A.M. Hammerum, and F.M. Aarestrup. 1998. Molecular analysis of Tn1546 in Enterococcus faecium isolated from animals and humans. J. Clin. Microbiol. 36:437-442. 
195. Jensen, L.B. 1998. Differences in the occurrence of two base pair variants of Tn1546 from vancomycin-resistant enterococci from humans, pigs, and poultry. Antimicrob. Agents Chemother. 42:2463-2464.

196. Moubareck, C., N. Bourgeois, P. Courvalin, and F. DoucetPopulaire. 2003. Multiple antibiotic resistance gene transfer from animal to human enterococci in the digestive tract of gnotobiotic mice. Antimicrob. Agents Chemother. 47: 2993-2996.

197. Dahl, K.H., D.D. Mater, M.J. Flores, P.J. Johnsen, T. Midtvedt, G. Corthier, and A. Sundsfjord. 2007. Transfer of plasmid and chromosomal glycopeptide resistance determinants occurs more readily in the digestive tract of mice than in vitro and exconjugants can persist stably in vivo in the absence of glycopeptide selection. J. Antimicrob. Chemother. 59:478-486.

198. Lester, C.H., and A.M. Hammerum. 2010. Transfer of vanA from an Enterococcus faecium isolate of chicken origin to a $\mathrm{CC} 17 \mathrm{E}$. faecium isolate in the intestine of cephalosporin-treated mice. J. Antimicrob. Chemother. 65:1534-1536.

199. Lester, C.H., N. Frimodt-Moller, T.L. Sorensen, D.L. Monnet, and A.M. Hammerum. 2006. In vivo transfer of the vanA resistance gene from an Enterococcus faecium isolate of animal origin to an E. faecium isolate of human origin in the intestines of human volunteers. Antimicrob. Agents Chemother. 50:596-599.

200. Phillips, I., M. Casewell, T. Cox, G.B. De, C. Friis, R. Jones, C. Nightingale, R. Preston, and J. Waddell. 2004. Does the use of antibiotics in food animals pose a risk to human health? A critical review of published data. J. Antimicrob. Chemother. 53:28-52.

201. Aarestrup, F.M. 2000. Characterization of glycopeptideresistant Enterococcus faecium (GRE) from broilers and pigs in Denmark: genetic evidence that persistence of GRE in pig herds is associated with coselection by resistance to macrolides. J. Clin. Microbiol. 38:2774-2777.

202. Butaye, P. 2013. Effects of antimicrobial usage on the development of antimicrobial resistance. Vet. J. 198: 307-308.

203. Hasman, H., and F.M. Aarestrup. 2005. Relationship between copper, glycopeptide, and macrolide resistance among Enterococcus faecium strains isolated from pigs in Denmark between 1997 and 2003. Antimicrob. Agents Chemother. 49:454-456.

204. Johnsen, P.J., J.I. Osterhus, H. Sletvold, M. Sorum, H. Kruse, K. Nielsen, G.S. Simonsen, and A. Sundsfjord. 2005. Persistence of animal and human glycopeptide-resistant enterococci on two Norwegian poultry farms formerly exposed to avoparcin is associated with a widespread plasmidmediated vanA element within a polyclonal Enterococcus faecium population. Appl. Environ. Microbiol. 71:159-168.

205. Kroll, J., S. Klinter, C. Schneider, I. Voss, and A. Steinbuchel. 2010. Plasmid addiction systems: perspectives and applications in biotechnology. Microb. Biotechnol. 3:634-657.

206. Kampmeier, S., D. Knaack, A. Kossow, S. Willems, C. Schliemann, W.E. Berdel, F. Kipp, and A. Mellmann. 2017. Weekly screening supports terminating nosocomial transmissions of vancomycin-resistant enterococci on an oncologic ward-a retrospective analysis. Antimicrob. Resist. Infect. Control. 6:48.

207. Willems, R.J., W. Homan, J. Top, M. van Santen-Verheuvel, D. Tribe, X. Manzioros, C. Gaillard, C.M. Vandenbroucke-
Grauls, E.M. Mascini, K.E. van, J.D. van Embden, and M.J. Bonten. 2001. Variant esp gene as a marker of a distinct genetic lineage of vancomycin-resistant Enterococcus faecium spreading in hospitals. Lancet. 357:853-855.

208. Rice, L.B., L. Carias, S. Rudin, C. Vael, H. Goossens, C. Konstabel, I. Klare, S.R. Nallapareddy, W. Huang, and B.E. Murray. 2003. A potential virulence gene, hylEfm, predominates in Enterococcus faecium of clinical origin. J. Infect. Dis. 187:508-512.

209. Woodford, N., M. Soltani, and K.J. Hardy. 2001. Frequency of esp in Enterococcus faecium isolates. Lancet. 358:584.

210. Arabestani, M.R., M. Nasaj, and S.M. Mousavi. 2017. Correlation between infective factors and antibiotic resistance in Enterococci clinical isolates in West of Iran. Chonnam. Med. J. 53:56-63.

211. Landete, J.M., A. Peiroten, M. Medina, J.L. Arques, and E. Rodriguez-Minguez. 2017. Virulence and antibiotic resistance of Enterococci isolated from healthy breastfed infants. Microb. Drug Resist. 2017 [Epub ahead of print]; DOI: $10.1089 / \mathrm{mdr} .2016 .0320$.

212. Aumeran, C., O. Baud, O. Lesens, J. Delmas, B. Souweine, and O. Traore. 2008. Successful control of a hospital-wide vancomycin-resistant Enterococcus faecium outbreak in France. Eur. J. Clin. Microbiol. Infect. Dis. 27:1061-1064.

213. Bourdon, N., M. Fines-Guyon, J.M. Thiolet, S. Maugat, B. Coignard, R. Leclercq, and V. Cattoir. 2011. Changing trends in vancomycin-resistant enterococci in French hospitals, 2001-08. J. Antimicrob. Chemother. 66:713-721.

214. Deplano, A., O. Denis, C. Nonhoff, F. Rost, B. Byl, F. Jacobs, V. Vankerckhoven, H. Goossens, and M.J. Struelens. 2007. Outbreak of hospital-adapted clonal complex-17 vancomycin-resistant Enterococcus faecium strain in a haematology unit: role of rapid typing for early control. J. Antimicrob. Chemother. 60:849-854.

215. Lopez, M., E. Cercenado, C. Tenorio, F. Ruiz-Larrea, and C. Torres. 2012. Diversity of clones and genotypes among vancomycin-resistant clinical Enterococcus isolates recovered in a Spanish hospital. Microb. Drug Resist. 18:484-491.

216. Jakovac, S., E.F. Bojic, M.A. Ibrisimovic, B. Tutis, M. Ostojic, and M. Hukic. 2017. Characteristics of vancomycin-resistant Enterococcus strains in the West Balkans: a first report. Microb. Drug Resist. 23:122-126.

217. Kuriyama, T., D.W. Williams, M. Patel, M.A. Lewis, L.E. Jenkins, D.W. Hill, and I.K. Hosein. 2003. Molecular characterization of clinical and environmental isolates of vancomycin-resistant Enterococcus faecium and Enterococcus faecalis from a teaching hospital in Wales. J. Med. Microbiol. 52:821-827.

218. Cavaco, L.M., H. Korsgaard, R.S. Kaas, A.M. Seyfarth, P. Leekitcharoenphon, and R.S. Hendriksen. 2017. First detection of linezolid resistance due to the optrA gene in enterococci isolated from food products in Denmark. J. Glob. Antimicrob. Resist. 9:128-129.

219. Falk, P.S., J. Winnike, C. Woodmansee, M. Desai, and C.G. Mayhall. 2000. Outbreak of vancomycin-resistant enterococci in a burn unit. Infect. Control Hosp. Epidemiol. 21:575-582.

220. Gambarotto, K., M.C. Ploy, P. Turlure, C. Grelaud, C. Martin, D. Bordessoule, and F. Denis. 2000. Prevalence of vancomycin-resistant enterococci in fecal samples from hospitalized patients and nonhospitalized controls in a 
cattle-rearing area of France. J. Clin. Microbiol. 38:620624.

221. Maraki, S., G. Samonis, D. Dimopoulou, and E. Mantadakis. 2014. Susceptibility of glycopeptide-resistant Enterococci to linezolid, quinupristin/dalfopristin, tigecycline and daptomycin in a Tertiary Greek Hospital. Infect. Chemother. 46:253-256.

222. Wang, S., Y. Guo, J. Lv, X. Qi, D. Li, Z. Chen, X. Zhang, L. Wang, and F. Yu. 2016. Characteristic of Enterococcus faecium clinical isolates with quinupristin/dalfopristin resistance in China. BMC Microbiol. 16:246.

223. Bender, J.K., C. Fleige, I. Klare, S. Fiedler, A. Mischnik, N.T. Mutters, K.E. Dingle, and G. Werner. 2016. Detection of a cfr(B) Variant in German Enterococcus faecium clinical isolates and the impact on linezolid resistance in Enterococcus spp. PLoS One. 11:e0167042.

224. Dobbs, T.E., M. Patel, K.B. Waites, S.A. Moser, A.M. Stamm, and C.J. Hoesley. 2006. Nosocomial spread of Enterococcus faecium resistant to vancomycin and linezolid in a tertiary care medical center. J. Clin. Microbiol. 44:3368-3370.

225. Rybak, J.M., and K. Roberts. 2015. Tedizolid phosphate: a next-generation oxazolidinone. Infect. Dis. Ther. 4:1-14

226. Fiedler, S., J.K. Bender, I. Klare, S. Halbedel, E. Grohmann, U. Szewzyk, and G. Werner. 2016. Tigecycline resistance in clinical isolates of Enterococcus faecium is mediated by an upregulation of plasmid-encoded tetracycline determinants tet(L) and tet(M). J. Antimicrob. Chemother. 71:871-881.

227. Si, H., W.J. Zhang, S. Chu, X.M. Wang, L. Dai, X. Hua, Z. Dong, S. Schwarz, and S. Liu. 2015. Novel plasmid-borne multidrug resistance gene cluster including lsa(E) from a linezolid-resistant Enterococcus faecium isolate of swine origin. Antimicrob. Agents Chemother. 59:7113-7116.

228. Ahmed, M.O., P.D. Clegg, N.J. Williams, K.E. Baptiste, and M. Bennett. 2011. Vancomycin resistant enterococci (VRE) in equine-faecal samples. In: A. Mendez-Vilas. Science and Technology Against Microbial Pathogens. Research, Development and Evaluation. World Scientific Publishing, Singapore, pp. 357-362.

229. Song, J.Y., I.S. Hwang, J.S. Eom, H.J. Cheong, W.K. Bae, Y.H. Park, and W.J. Kim. 2005. Prevalence and molecular epidemiology of vancomycin-resistant enterococci (VRE) strains isolated from animals and humans in Korea. Korean J. Intern. Med. 20:55-62.

230. Nomura, T., K. Tanimoto, K. Shibayama, Y. Arakawa, S. Fujimoto, Y. Ike, and H. Tomita. 2012. Identification of VanN-type vancomycin resistance in an Enterococcus faecium isolate from chicken meat in Japan. Antimicrob. Agents Chemother. 56:6389-6392.
231. Holzel, C., J. Bauer, E.M. Stegherr, and K. Schwaiger. 2014. Presence of the vancomycin resistance gene cluster vanC1, vanXYc, and vanT in Enterococcus casseliflavus. Microb. Drug Resist. 20:177-180.

232. Ray, A.J., N.J. Pultz, A. Bhalla, D.C. Aron, and C.J. Donskey. 2003. Coexistence of vancomycin-resistant enterococci and Staphylococcus aureus in the intestinal tracts of hospitalized patients. Clin. Infect. Dis. 37:875-881.

233. Tosh, P.K., and L.C. McDonald. 2012. Infection control in the multidrug-resistant era: tending the human microbiome. Clin. Infect. Dis. 54:707-713.

234. Mathew, A.G., R. Cissell, and S. Liamthong. 2007. Antibiotic resistance in bacteria associated with food animals: a United States perspective of livestock production. Foodborne. Pathog. Dis. 4:115-133.

235. van den Bogaard, A.E., R. Willems, N. London, J. Top, and E.E. Stobberingh. 2002. Antibiotic resistance of faecal enterococci in poultry, poultry farmers and poultry slaughterers. J. Antimicrob. Chemother. 49:497-505.

236. Heuer, O.E., A.M. Hammerum, P. Collignon, and H.C. Wegener. 2006. Human health hazard from antimicrobialresistant enterococci in animals and food. Clin. Infect. Dis. 43:911-916.

237. Conwell, M., V. Daniels, P.J. Naughton, and J.S. Dooley. 2017. Interspecies transfer of vancomycin, erythromycin and tetracycline resistance among Enterococcus species recovered from agrarian sources. BMC Microbiol. 17:19.

238. Hammerum, A.M., C.H. Lester, and O.E. Heuer. 2010. Antimicrobial-resistant enterococci in animals and meat: a human health hazard? Foodborne. Pathog. Dis. 7:1137-1146.

239. Schwaiger, K., J. Bauer, S. Hormansdorfer, G. Molle, P. Preikschat, P. Kampf, I. Bauer-Unkauf, M. Bischoff, and C. Holzel. 2012. Presence of the resistance genes vanC1 and pbp5 in phenotypically vancomycin and ampicillin susceptible Enterococcus faecalis. Microb. Drug Resist. 18:434-439.

Address correspondence to: Mohamed O. Ahmed, PhD Department of Microbiology and Parasitology Faculty of Veterinary Medicine University of Tripoli P.O. Box 13662 Tripoli Libya

E-mail: a.mo@live.com; m.ahmed@uot.edu.ly 